\title{
Kernos
}

Revue internationale et pluridisciplinaire de religion grecque antique

12| 1999

Varia

\section{Imago Iliadis. Le Bouclier d'Achille et la poésie de l' Iliade}

\author{
Danièle Aubriot-Sévin
}

\section{OpenEdition}

Journals

\section{Édition électronique}

URL : http://journals.openedition.org/kernos/706

DOI : $10.4000 /$ kernos.706

ISSN : 2034-7871

\section{Éditeur}

Centre international d'étude de la religion grecque antique

\section{Édition imprimée}

Date de publication : 1 janvier 1999

Pagination : 9-56

ISSN : 0776-3824

\section{Référence électronique}

Danièle Aubriot-Sévin, «Imago Iliadis. Le Bouclier d'Achille et la poésie de l'lliade », Kernos [En ligne],

12 | 1999, mis en ligne le 13 avril 2011, consulté le 20 avril 2019. URL : http://journals.openedition.org/ kernos/706 ; DOl : 10.4000/kernos.706 
Kernos, 12 (1999), p. 9-56.

\title{
Imago Iliadis ${ }^{1}$
}

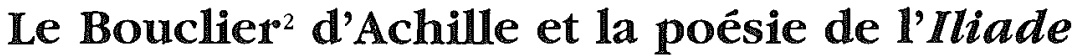

\author{
À la mémoire de Jules Labarbe
}

1 Cette expression est une allusion évidente au bel article de P.R. Hardie, Imago Mundi: Cosmological and Ideological Aspects of the Shield of Acbilles, in JHS, 105 (1985), p. 11-31 (infra Hardie), qui s'intègre dans toute une suite de travaux : $c f$. entre autres Helbig, L'épopée bomérique expliquée par les monuments, trad. Trawinsky, Paris, 1894, p. 508-511; W. Schadewald, Von Homers Welt und Werk, Stuttgart, $1965^{4}$ [1938], p. 352-374: E.T. OwEn, The Story of the Iliad, Toronto, 1946, réimpr. Ann Arbor, 1966, p. 186-189; G.A. Duethorn, Acbilles' Sbield and the Structure of the Iliad, Amherst, 1951 (non vidi); K. Reinhardt, Die Ilias und ibr Dichter, Göttingen, 1961 [1956], p. 401-411; $\varnothing$. ANDERSEN, Some Thoughts on the Shield of Acbilleus, in SO, 51 (1976), p. 5-18 (infra, Tbougbts) et la bibliographie qu'il indique p. 5 \& 6; M.M. WILlcock, $A$ Companion to the Iliad, Chicago, 1976, p. 209-214; M.W. Edward, Homer, Poet of the Iliad, Baltimore \& London (1987), 1990, p. 278-286; Jackie Pigeaud, Le Bouclier d'Achille, in $R E G, 101$ (1988), p. 54-63, spéc. p. 60; K. STANLEY, The Shield of Homer. Narrative Structure in the Iliad, Princeton, 1993 (bibliographie p. 303, n. 3). L'interprétation des scènes agencées sur le Bouclier comme un microcosme n'est pas récente : depuis l'Antiquité ( $c f$. les références indiquées par Michèle Biraud, Lectures du Bouclier d'Achille, Suppl, au Bull. $n^{\circ} 20$ de l'Assoc. des Enseignants de Langues anciennes de l'Acad. de Besançon, 1982, p. 3 sq.) cette interprétation a reçu des éclairages différents suivant que l'accent était mis sur un découpage entre mondes cosmique, social, rural (J.M. REDFIELD, Nature and Culture in the Iliad: the Tragedy of Hector, Univ. of Chicago Pr., 1975, p. 187), sur un éventuel reflet de la tripartition indo-européenne (At. YoshIDA, La structure de l'illustration du Bouclier d'Acbille, $R B P H$, 42 [1964], p. 5-15, suivi par Biraud, p. 14-15), ou sur la représentation cosmique comme emblème du pouvoir (Hardie, p. $22 \mathrm{sq}$.). Taplin donne un aperçu sur ces points de vue, en insistant sur la succession des saisons, et en introduisant certains rapprochements sporadiques avec des thèmes présents dans l'Iliade (O. TAPLIN, The Shield of Acbilles within the Iliad, in $G \mathcal{E} R, 27$ [1980], p. 1-21, cité infra Sbield). Tant pour les références bibliographiques que pour mainte discussion de détail, je me permets de renvoyer à cet article très riche.

2 Ici et dans la suite de cette étude, nous écrivons Bouclier pour désigner le passage du chant XVIII de l'lliade ( $v$. 483-608). Nous écrirons bouclier pour désigner l'objet. Signalons pour n'y plus revenir que nous laisserons entièrement de côté les détails techniques qui ont pu être abordés ici ou là, si instructifs puissent-ils être à l'occasion (ainsi de D.H.F. GraY, Metal-Working in Homer, in JHS, 74 [1954], p. 1-15, dont la lecture permet de constater que tous les métaux connus des poèmes homériques entrent dans la fabrication du bouclier, sauf le fer : p. 12). 
Point n'est question ici de prétendre épuiser les implications d'un passage qui a déjà fait couler beaucoup d'encre, non plus que de revenir sur les multiples interprétations ${ }^{3}$ qui en ont été proposées ou de les discuter. Une telle ambition excéderait de beaucoup les limites d'un article. Aussi loin de sacrifier à une mode que d'aspirer à renouveler à tout prix la lecture d'un texte déjà si étudié, notre seul propos sera d'attirer l'attention sur un possible rapport entre cette séquence prétendûment descriptive et le récit qu'est l'Iliade. Seront considérés aussi bien le point de vue de la diégèse que celui de la narration ${ }^{4}$, en vue d'ouvrir des perspectives sur la signification de cette épopée.

Il semble superflu de situer longuement l'épisode. Il prend place, comme nul ne le méconnaît, à un moment d'émotion culminant : le héros, à la nouvelle de la mort de Patrocle, décide d'effectuer une palinodie totale par laquelle son intérêt personnel cède le pas à la solidarité avec ses compa-

3 Sans prétendre récuser les interprétations des études citées à la n. 1, qui peuvent toutes se justifier à certains égards, nous nous plaçons sur un autre terrain, celui du rapport à l'ouvre prise comme un tout. Non qu'il soit question pour autant d'explorer l'aspect proprement esthétique de ce texte. Il a été abordé dans deux livres brillants : Jackie Pigeaud, L'art et le vivant, Paris, 1995; A.S. Becker, The Sbield of Acbilles, and the Poetics of Ekpbrasis, Lanham, 1995 (qui avait été précédé d'un article : The Sbield of Acbilles and the Poetics of Homeric Description, in AJPb, 111 [1990], p. 139-153) sur lesquels nous ne revenons pas, quels que soient leurs mérites. La question avait retenu aussi Christine Hunzinger, Le plaisir estbétique dans l'épopée archaïque, in BAGB (1994), p. 4-30. Nous n'abordons pas davantage l'intrication des « points de vue », pourtant remarquable puisque cette prétendue description (où culmine bien évidemment la " thématique du spectacle » - l'expression est de Françoise Frontisi-Ducroux, La citbare d'Acbille, Rome, 1986 [Biblioteca di Quademi Urbinati di Cultura classica, 1], p. 62 - qui court dans tout le poème) superpose toutes les distanciations : celle du dieu (Héphaïstos), qui a sur les tribulations humaines une vue « cavalière »; celle de l'artiste (l'illustre Boiteux), qui « réfléchit » à l'organisation de son œuvre « dans ses savants pensers 》 (v. 482); celle du poète, qui tire les fils et de la description (le Bouclier) et du récit (les scènes d'atelier faisant le lien avec l'entremise de Thétis pour son fils); et enfin celle du public appelé à contempler en imagination à la fois cette ouvre, sa fabrication, et sa présentation à la déesse (sans compter qu'à l'intérieur du Bouclier, les scènes artistiques sont elles-mêmes l'objet de spectacles qui rassemblent la foule (v, 496; 570; 604). Toutes ces questions qui concernent la narratologie sont fort débattues depuis un certain temps. Je me contente sur ce point de renvoyer aux études de $\mathrm{Cl}$. Calame, le récit en Grèce ancienne. Énonciations et représentations de poètes, Paris, 1986, et d'Irène J.F. DE JoNG, Narrators and Focalizers. The Presentation of the Story in the Iliad, Amsterdam, 1987, entre autres.

4 Pour reprendre la terminologie de G. Genetre, Figures III, Paris, Seuil, 1972, p. 72. Précisons donc nettement que les termes seront employés ici dans les conditions suivantes : " diégèse " pour ce qui concerne le contenu, les thèmes de l'histoire racontée, en somme la succession des événements relatés; et "narration » pour l'ensemble des procédés poétiques. La "narration " à son tour sera considérée selon deux modalités : l'une, qui sera nommée "récit» quand sera en cause la mise en cuvre littéraire de la geste épique proprement dite; l'autre, qui sera nommée "contre-récit », quand il s'agira des " comparaisons". 
gnons, ce qui, il le sait et l'accepte, doit entraîner promptement sa propre mort; en sorte que par cette décision il se convertit, si l'on peut dire, à l'humanités. Au point de vue du récit comme à celui de l'action dramatique, nous sommes à un tournant puisque à deux reprises dans ce chant Thétis est amenée, pour Achille et pour Héphaïstos respectivement, à dresser un bilan de l'lliade $e^{6}$. Ainsi pendant que la déesse par deux fois souligne la responsabilité de son fils dans la mort de Patrocle et annonce une fois de plus le trépas du Péléide ${ }^{7}$, le poète utilise avec vigueur ces deux discours lirects pour résumer tout l'enchaînement qui a mené à cette situation, avant de donner une nouvelle impulsion aux événements. Enfin, au seuil de son engagement fatal dans l'action, au moment où le héros quitte son rôle de spectateur $r^{8}$ - qui lui permettait de chanter les exploits des guerriers - pour devenir acteur (donc matière du récit), Achille est relayé par Héphaistos pour faire ouvre d'artiste. Sans doute cette «description »" d'une pièce de la

5 Cf. Danièle Aubriot, Le Divin Acbille et l'exaltation de l'bumain dans l'Tliade, in Antbropologie et Humanisme, in Cabiers de l'ENS Fontenay, n ${ }^{\circ}$ 39-40 (1985), p. 9-29, et Humanité et divinité dans l'lliade à travers le personnage d'Achille, à paraître dans les Mélanges Fernand Robert. K.J. AтchiтY, Homer's Iliad. The Shield of Memory, Southern Illinois Univ. Pr., 1978 avait bien vu la palinodie, mais l'avait située sur un plan social en s'attachant au «passage » entre l'état d'un jeune homme occupé de ses droits à celui d'un adulte plus sensible à ses responsabilités vis-à-vis de la communauté. De toute évidence, ce changement d'attitude est comme concrétisé par le changement d'armure du héros ( $c f$. Phanis J. Kakridis, Achilleus' Rüstung, in Hermes, 89 [1961], p. 288-297), qui se résout à assumer sa pleine humanité au moment même où il enfile son armure divine. Dans la même perspective, on peut faire observer que le poète prend soin d'éloigner clairement cette scène chez Héphaïstos dans le monde divin, en la situant entre un échange de répliques entre Zeus et Héra ( $v$. 356-367) et une localisation très nette sur l'Olympe neigeux (v. 616). On ne saurait mieux suggérer combien Achille, dans sa douleur humaine, est à l'écart de ces hauteurs. Cf. infra, p. 49-50.

6 Pour Achille, Thétis souligne brutalement (en quatre vers : 74-77) le lien entre la colère qu'il n'a pas su dominer et la mort de Patrocle; pour Héphaïstos elle reprend les choses de plus haut, à son mariage, et les mène plus loin, à la mort " programmée » d'Achille, après mainte souffrance (v. 429-461). Cf. V. Dr BenedetTo, Nel laboratorio di Omero, Turin, 1994, p. 57-59; R. Di DonATo, Omero: forme della narrazione e forme della realta. Lo scudo di Acbille, in S. SETris (éd.), I Greci. Storia, cultura, arte, società. 2. Una storia greca. I. Formazione, Torino, Einaudi, 1996, p. 227-253, spéc. p. 232.

7 Ces annonces du destin d'Achilie vont se précisant et se rapprochant au fil du texte : Il. I, 352-3; IX, 410 sq.; XVI, 853; XVIII, 95; XIX, 328; 409; XXI, 110; XXII, 360; XXIII, 80; XXIV, 540 .

8 Puisque lui aussi, comme Zeus, était montré à l'écart des vicissitudes du combat, « contemplant» de loin l'action ( $\epsilon$ loopówv en rejet: VIII, 52; XI, 82 pour Zeus; XI, 601 pour Achille). Aussi la seule «activité » dans laquelle le poète l'avait décrit impliqué était-elle, au chant IX, le chant ( $v, 186 \mathrm{sq}$.).

9 De fait c'en est si peu une qu'on a du mal à se représenter le bouclier en question. Il n'est que de voir les difficultés auxquelles se heurtent les restitutions proposées. $C f . \mathrm{K}$. Fittschen, Der Scbild des Acbilleus, Arcbaeologia Homerica, II, N, Göttingen, 1973; E. VANDERLINDEN, Le Bouclier d'Acbille, in LEC, 48 (1980), p. 97-122, spéc. p. 98, n. 4; Hardie, p. 18-22 (cf. supra, n. 1); Edwards (1990, supra, n. 1), p. 279-280; M.W. Edwards, The Iliad: 
nouvelle armure que Thétis prie le dieu d'ouvrer pour son fils au seuil du trépas constitue-t-elle dans le récit une pause propre à délasser de ces émotions ${ }^{10}$. Peut-être aussi cette « digression » contribue-t-elle à faire vibrer l'importance de l'action ainsi suspendue ${ }^{11}$. C'est probable; mais ce n'est pas tout. Trop de soin est apporté aux correspondances entre ce chef-d'œuvre et le poème pour qu'on voie dans cette apparente description un simple « arrêt sur image »: cette stase pourrait bien constituer un creuset où l'ouvrage entier se recompose selon une autre alchimie de nature à éclairer son sens profond. Par conséquent, il ne s'agira pas seulement ici de dégager la valeur emblématique de ce Bouclier ${ }^{12}$, quoiqu'on ne puisse se dispenser de l'avoir présente à l'esprit : l'attention portera surtout sur un examen des procédés poétiques mis en œuvre.

\section{1. $I^{\text {re }}$ partie (v. 490-540): la mise en abyme diégétique (et déjà en partie narrative) de l' Iliade}

Le parallèle peut-être à la fois le plus extérieur et le plus patent à établir entre l'œuvre du dieu et celle du poète concerne la composition. L'architecture du Bouclier en effet obéit (comme l'Iliade entière) à une règle d'orga-

A Commentary, ed. G.S. KIRK, vol. V, Cambridge, 1991, p. 203-207. De plus le caractère dynamique (et sonore!) des scènes décrites empêche absolument de s'abandonner à la fiction de l'objet simplement matériel : sur le refus par le poète de tout effet d'illusion réaliste, $c f$. PigeAud, 1988 (supra, n. 1), p. 55-56. On ne peut pas prétendre davantage que l'attention soit attirée sur les phases de la fabrication de l'objet, comme on semble d'ordinaire le tenir pour plus ou moins acquis en emboîtant le pas à Lessing (G.E. Lessing, Laocoon ou Des Frontières de la peinture et de la poésie (paru en 1766), Paris, 1990 [trad. fr. Courtin], chap, 17-19). Ce point était repris par F.M. STAwell, Homer and the Iliad, Londres, 1909, p. 197 sq. ou par H.A. GäRTNER, Beobacbtungen zum Scbild des A., in H. Görgemanns \& E.A. Schmidt (éds), Studien zum antiken Epos, Meisenheim am Glan, 1976, p. 46-65. Sans doute ces phases sont-elles mentionnées au début ( $v$. 474-477), mais on n'en entend plus parler ensuite (les v. 609-613 concernent les autres pièces de l'armure). De fait, l'œuvre d'art, ce qui y figure (en mouvement), ainsi que la fabrication, sont mentionnés d'emblée, mais de manière elliptique. Ce parti-pris a pour effet de donner tout son relief à l'organisation discursive de l'énumération de scènes qui suit; cela aboutit à suggérer une conception abstraite, à mettre en évidence une structure, bien plus qu'à fournir une quelconque « description » d'un objet. Cette question du rapport entre narration et description à l'intérieur de ce texte a été abordée dans un article très général, que celui-ci vient prolonger : Danièle Auвriot, Représentation plastique et récit poétique: le Bouclier d'Achille ou les cuures d'art en miroir, in De la palette à l'écritoire, Actes réunis par Monique CHFFdor, I, Nantes, 1997, p. 25-35 (infra: 1997a).

10 Cf. TAPlin, Sbield (1980), p. 3 (cf. supra, n. 1). L'A. insiste bien également (ibid.) sur le fait qu'il serait vain de prétendre chercher un correspondant archéologique à l'arme ainsi « décrite ».

11 N. Austin, The Function of Digressions in the Iliad, in GRBS, 7 (1966), p. 295-312, spéc. p. 307-308. Di Donato (supra, n. 6), p. 229-230.

12 Sans doute appartient-il par nature à un bouclier de signifier quelque chose de celui qui le porte et du combat où il sera plongé. C'est en tout cas devenu une tradition poétique (longuement illustrée par Les Sept contre Thèbes) de l'entendre ainsi. 
nisation annulaire typique de l'époque archaïque. Ainsi (pour ne retenir qu'un seul exemple), dans le poème au chant XXIV, le compte des jours écoulés reprend dans l'ordre inverse celui du chant I (1-9-1-12 // 12-1-9-1) tout comme se répondent en un sens les scènes de Chrysès et de Priam ${ }^{13}$. Le Bouclier, de même, est présenté sur une séquence de $4+5$ vers (les préparatifs, v. 474-7, puis la conception d'ensemble, v. 478-482), et quitté sur la séquence inverse de $5+4$ vers (le reste de l'armure ${ }^{14}, v, 609-613$, puis la présentation à Thétis, v, 614-617), tandis que l'Océan mentionné à la fin (v. 607) renvoie évidemment à l'Océan (v. 489) intégré au Cosmos du début (v. 483-9). Cette structure en boucle ${ }^{15}$, qui régit l'une comme l'autre expression artistique (de poésie et d'orfèvrerie), peut bien être solidaire d'une sorte

13 Le pionnier dans ces recherches formelles sur le texte homérique est sans doute J. Sheppard dans son livre fondamental The Pattern of the Iliad, Londres, 1922, suivi par J.L. MYRES, (Who were the Greeks?, Berkeley, California, 1930, p. 517 sq.; The Structure of the Iliad, illustrated by the Speeches, in JHS, 74 [1954], p. 122-141) et par C.H. WHITMAN, Homer and the Heroic Tradition, Cambridge Mass., 1958, p. $256 \mathrm{sq}$. En même temps, la composition annulaire a donné lieu à une étude générale de B.A. VAN GroningEN, $L a$ composition littéraire archaïque grecque, Amsterdam, 1958. Celle des scènes du Bouclier est bien mise en évidence par GÄrTNER (supra n. 9), p. 53 sq. On pourra aussi consulter Fr. Létoublon, Le miroir et la boucle, in Poétique, Revue de Théorie et d'Analyse Littéraires, Paris, 1983, p. 19-36, et, sur les scènes comparées de Chrysès et de Priam, Danièle Aubriot, Remarques sur le chant $I X$ de l'tiade, in BAGB (1985), p. 257-279 (infra, Il. IX), spéc. p. 268 sq.; R.J. RABEL, Chryses and the Opening of the Iliad, in AJPb (1988), p. 473-481, spéc. p. 473, n. 3. L'une des analyses les plus complètes est sans doute celle de StaNLEY (supra, n. 1), p. 6 sq.

14 Dont il vaut la peine de souligner qu'elle ne comporte que des armes défensives, puisque la pique en bois du Pélion est la seule pièce qui reste de l'ancienne panoplie (cf. R.S. Shannon, The Arms of Achilles and Homeric Compositional Technique, Leiden, 1975 [Mnemosyne Suppl. 36], p. 27), et qu'il n'est rien dit d'une épée (ni aux v. 458-460, ni aux v. 609-613 d'Il. XVIII).

15 Puisque l'aède énumère les différents motifs dont le dieu orne le bouclier du héros sans souci discernable de les situer les uns par rapport aux autres, il est commode - et de bonne méthode - de classer ces motifs en fonction des verbes qui sont employés pour les présenter. C'est ainsi qu'on est amené à indiquer le schéma suivant : É $T \epsilon \nu \xi \epsilon$ (il

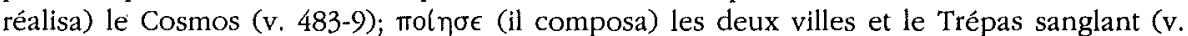

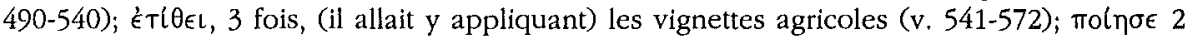
fois, (il composa) les vignettes pastorales (v. 573-589); nolkı $\lambda \lambda \epsilon$ (il s'employa à l'orner) du

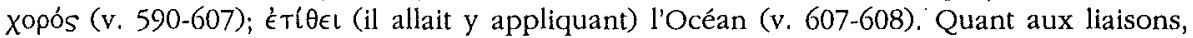
on pouvait difficilement marquer un plus grand éloignement pour la variatio sermonis

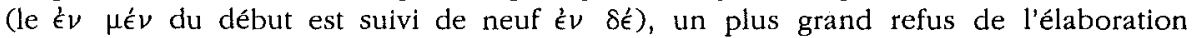
syntaxique (quelques relatives : v. $487 ; 488 ; 508 ; 520 ; 521 ; 591$; quelques temporelles : 544 ; 566; 520; 530; une comparaison introduite par $\omega$ s $\delta T \epsilon:$ v. 600; une conditionnelle : 601); des passages entiers sont marqués par la parataxe. Même si l'on fait la part des habitudes homériques, un pareil désir de juxtaposition ne peut que frapper. De même, chaque scène se détache sur l'œuvre immortelle indépendamment des autres, sans avant ni après, ni dessus ni dessous, le seul « ordre » résidant dans la succession du texte. Cela ne saurait être une inadvertance (sur cette succession, plus temporelle que spatiale, des scènes, $c f$. Françoise Frontrisı-Ducroux, Dédale. Mythologie de l'artisan en Grèce ancienne, Paris, 1975 , p. 74-76). 
d'esthétique avant la lettre; mais il n'est pas impossible qu'elle soit aussi révélatrice d'une certaine conception de la vie et du monde fondée sur la réversibilité.

Par ailleurs, on retrouve entre le Bouclier et le poème de multiples correspondances plus ou moins nettes, qui viennent corroborer l'interprétation (maintenant admise volontiers) de ce passage comme une « mise en abyme $"{ }^{16}$ du récit de la guerre entre Troyens et Achéens. Il s'agit (dans la

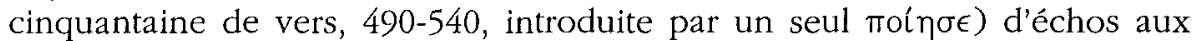
thèmes ou à l'expression formelle de l'action sous les murs de Troie, qui forme la trame de l'épopée Les correspondances, très vagues au début, gagnent en netteté à mesure que progresse la « description ». D'abord la ville en paix qui ouvre ce morceau peut passer pour une sorte de raccourci général et comme désincarné de l'lliade, de ses péripéties, de ses belligérants. On observe en effet d'un côté des noces, qui semblent contenir une évocation large de la vie florissante de Troie dans le passé, et principalement de l'union d'Hector et d'Andromaque dont le poème offre plus d'un rappel (en particulier VI, 395-398 et XXII, 471-472); de l'autre, la scène « du procès », dont le rapport à la « colère d'Achille » et au fil directeur du poème n'est plus à démontrer ${ }^{17}$. Quant à la ville en guerre, elle peut être regardée comme une projection abstraite de Troie assiégée. Les deux armées qui l'investissent avec des vues divergentes sur la bonne stratégie à adopter font penser à la coalition divisée des Achéens. Mais surtout certaines répétitions littérales d'hémistiches ou de vers qu'on retrouve ailleurs (avant ou après notre passage) représentent une invitation quasiment explicite à effectuer des rapprochements avec plusieurs endroits de l'épopée. Ainsi la discussion qui divise les assiégeants de la ville en guerre (« poursuivre la ruine de la ville entière, ou faire deux parts de toutes les richesses... »v. 510-512) rappelle-t-elle certes la scène « du procès » qui vient d'être figurée (v. 498-501), où l'intransigeance s'opposait à l'acceptation de compromis - dans le droit fil des discours

16 Quoiqu'elle reprenne à son compte cette expression (devenue presque un Tómos pour désigner ce passage, mais d'un point de vue ordinairement diégétique), M. Biraud affirme (supra, n. 1), p. 8 qu'avec la description du bouclier « la narration s'interrompt pour laisser place à la description d'un autre univers sans rapport narratif avec le reste de l'Iliade » (p. 9); Edwards (1990, cf. supra, n. 1) sous-entend la même chose, p. 278. Mon but est précisément de montrer le contraire; Aтchiтy (supra, n. 5) avait confusément amorcé une idée comparable, mais l'étude la plus suggestive en ce sens se trouve dans S.L. ScheIn, The Mortal Hero. An Introduction to Homer's Iliad, Berkeley, 1984, p. 141-142.

17 On trouvera des éléments dans H. Hommel, Die Gericbtsszene auf dem Scbild des Acbilleus. Zur Pflege des Recbts in bomeriscber Zeit, Palingenesia 1969, 4, p. 11-38; L. Ch.

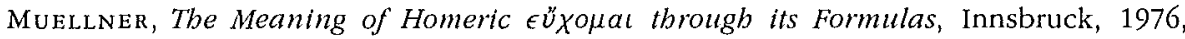
p. 105-6; Andersen, Thoughts (supra, n. 1), p. 11, et Myth, Paradigm and Spatial Form in the Iliad, in J.M. Bremer, I.J.F. De Jong, J. KALFF (éds), Homer beyond Oral Poetry. Recent Trands in Homeric Interpretation, Amsterdam, 1987, p. 1-14, spéc. p. 9. Voir aussi Edwards, 1990 (supra, n. 1), p. 281; G. NAGY, Pindar's Homer: the Lyric Possession of an Epic Past, Baltimore, 1990, p. 251 sq.; R. Westвrook, The Trial Scene in the Iliad, in HSCP, 94 (1992), p. 53-76; Di Donato (supra, n. 6), p. 238 sq. 
adressés à Achille dans l'Ambassade ${ }^{18}$; mais elle renvoie également à la division entre Polydamas et Hector, dont l'un conseillait au début du chant XVIII un combat sans quartier tandis que l'autre préférait une tactique de prudence (v. 243-313); enfin elle constitue surtout une anticipation textuelle des regrets d'Hector au seuil du combat fatal, quand il se laisse un instant aller à songer qu'il pourrait proposer à Achille de « faire deux parts de toutes les richesses... " (XXII, 117-121) ${ }^{19}$. Un rapprochement du même ordre semble se recommander pour le rempart, défendu par les femmes, les enfants, les vieillards, du vers 514 : sans doute la seule mention des murailles est-elle déjà une allusion large à Troie ${ }^{20}$. Mais le retour ici de la formule précise ẳ

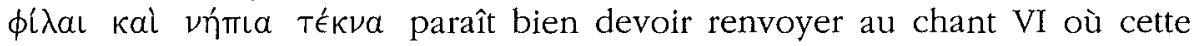
séquence rythmique ne revient pas" moins de trois fois $(95 ; 276 ; 370$ - sans compter ses autres occurrences ${ }^{21}$ ). Ce ne sont là que deux exemples de concomitances formelles irrécusables mais d'autres allusions viendraient s'ajouter $^{22}$, contribuant à attirer l'attention sur les multiples correspondances

18 Cf. Aubriót, Il. IX (supra, n. 13), p. 271-275, puis Prière et conceptions religieuses en Grèce ancienne, Lyon, 1992, p. 206.

19 Ce rapprochement - figurant déjà dans une scholie : cf. Di Donato (supra, n. 6, n. 51) - a été fait par O. TAPLIN, Homeric Soundings. The Shaping of the Iliad, Oxford, 1992, p. 234-235, mais nous nous éloignons de son interprétation qui proposait d'y voir « a standard clause ».

20 S. Scullx, Homer and the Sacred City, Ithaca Cornell Univ. Pr., 1990, p. 32 sq.

21 Cf. ANDERSEN, Thoughts (supra, n. 1), p. 10.

22 Ainsi peut-être le détail de l'abreuvoir, de la retraite coupée (тá $\mu \nu$ ovto à l'initiale du v. 528) doit-il faire penser aux péripéties de la course d'Hector coupé de Troie (XXII, 198) auprès des lavoirs, scène dont l'importance dans la mort du héros a été bien marquée par D. Bouvien, Mourir près des fontaines de Troie. Remarques sur le problème de la toilette funéraire d'Hector dans l'Tliade, in Euphrosyne (1987), p. 9-29, spéc. p. 15 (cf. aussi J. Griffin, Homeric Patbos and Objectivity, in $C Q, 26$ [1976], p. 161-187, spéc. p. 167, et Homer on Life and Death, Oxford, 1980, p. 22; 108-109). Aussi bien peut-on, à maint point de vue, rapprocher les chants VI et XXII, tous deux si présents à travers les allusions de ce passage-ci : $c f$. Ch. SEGAL, Andromache's Anagnorisis : Formulaic Artistry in Iliad XXII, 437-476, in HSCP, 75 [1971], p. 33-57 : p. 46 sq; Scully (supra, n. 20), p. 42-43. D'une manière générale, ces correspondances perceptibles à travers l'œuvre sont de mieux en mieux reconnues; citons entre autres Françoise Bader qui a examiné pour sa part divers exemples de "liages" (Une dizaine de comparaisons dans l'tliade : composition discontinue et aritbmétique, in Faits de langues, 5 [1995], p. 217-231; et Études de phonologie poétique: liages en composition discontinue, allitérations, inventaires, à paraître); de son côté D. BABUT, étudiant lui aussi un passage soupçonné d'être une addition tardive, avait été amené à constater combien ces scènes apparemment les plus suspectes étaient unies organiquement au reste du poème (Sur trois scènes des Jeux funèbres en l'bonneur de Patrocle (Iliade 23, 798-883), in Arcbitecture et poésie, bommage à G. Roux, Lyon, 1989 [CMO, 19], p. 133-147, spéc. p. 140); par ailleurs, la cohérence interne des poèmes homériques résulte encore de l'étude méthodique apportée par les deux livres de P. FortasSIER, L'bialus expressif dans l'Tliade et dans l'Odyssée, Louvain, 1988, et Le spondaique expressif dans l'Tliade et dans l'Odyssée, Louvain, 1995 - tant il est vrai que, de quelque point de vue qu'on se place, les liens tissés à travers le texte de l'lliade ressortent en pleine lumière, pour peu qu'on y prête attention. 
qui peuvent lier une locution employée pour les scènes du Bouclier à d'autres passages, même éloignés, de l'Iliade.

Peut-être est-il nécessaire de nous arrêter un instant sur ce que nous entendons par «échos». Pour frappantes qu'elles soient parfois, ces similitudes (par rapport au contenu du récit ou à sa forme) ne sauraient passer pour de simples appels à la mémoire (volontaire ou involontaire), puisqu'elles mettent en jeu des correspondances dont certaines ne pourront être perçues qu'après le chant XVIII (en particulier tout ce qui a trait à la mort d'Hector). De toute évidence cette attention portée aux récurrences littérales ou thématiques n'a de sens que si l'on accepte de regarder le poème comme un tout organique, dont il est légitime d'embrasser la trame entière d'un seul regard. Consentir à faire cette démarche est la condition requise pour concevoir que de ce tout l'e̋ $\kappa \phi \rho a \sigma ı \varsigma^{23}$ offerte par le Bouclier puisse être considérée comme une pièce essentielle. Ce que nous venons d'examiner nous permet déjà de dire qu'à nos yeux c'en est une réfraction « abstraite », pour plusieurs raisons : d'abord en ce qu'elle en offre une vue générale, anticipée tout autant que rétrospective; ensuite en ce qu'elle en propose un équivalent anonyme, exempt de toute contingence de patrie, de famille ou de lieu pour les personnages figurés; enfin en ce que la perspective adoptée est en quelque manière inversée par rapport à celle du poème : nous en voudrions pour preuve la présentation ici faite (v. 516-519) de deux dieux qui dans l'Iliade sont antagonistes, et qu'on va même voir s'affronter au chant XXI (v. 400-414) en une scène burlesque où Athéna abat Arès. Or sur le Bouclier ces deux figures sont non seulement côte à côte (l'emploi du duel est significatif), mais splendides de leur or immortel, et plus grandes que les hommes - tant il semble essentiel à l'imagerie du Bouclier de bien insister sur

23 C'est le terme d'usage, et le texte présent en est le prototype. Nous nous conformons donc à l'habitude en usant de ce mot, même s'il ne nous semble pas vraiment approprié - en ce que é $\kappa^{-}$semble suggérer qu'il s'agit d'un « hors-d'œuvre ». Il est vrai que Zénodote athétisait ce passage : $c f$. W. LeAf, The Iliad, vol. II, reprint Hakkert, Amsterdam, 1960, Appendix 1, p. 607, \& Pigeaud, 1988 (supra, n. 1), p. 59, n. 14. Or c'est précisément le bien-fondé de cette expulsion que nous contestons. À vrai dire, la démarche n'est pas neuve, et les protestations semblent avoir eu raison de cette manière de considérer le Bouclier comme une "digression inorganique ». Mais les raisons qui les ont motivées sont extrêmement variées. Par ex. R.L. Arrigon, Symbolism in the Shield of Acbilles, CB, 36 (1974), p. 49-50 se contentait encore d'un rapprochement lâche, fondé sur une opposition de la paix à la guerre, du bien au mal. Un grand chemin a été parcouru jusqu'à Becker,

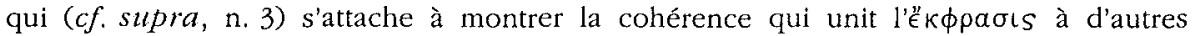
procédés poétiques mis en cuvre dans l'Iliade. Le projet qui me retient ici est encore

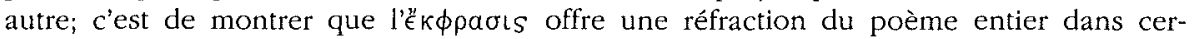
taines de ses formules, dans ses thèmes comme dans ses procédés narratifs, mais aussi

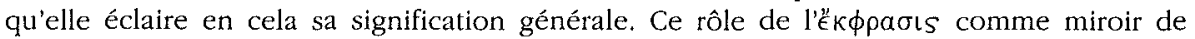
l'œeuvre littéraire qui la contient est bien dégagé (à propos d'une ouvre tributaire de l'épopée homérique) par M. Marcelle J. LAPlACE, L'emblème estbétique des Ethiopiques d'Héliodore: une bague d'ambre au chaton d'an'itbyste gravée, in Poésie et lyrique antiques, Lille, 1996 (P.U. Septentrion), p. 179-202, spéc. p. 191-192. 
l'irrémédiable différence qui sépare en deux blocs dieux et mortels, alors que le cours de l'lliade se plaît ailleurs à projeter chez les premiers les divisions qui opposent les seconds ${ }^{24}$. La référence à un procédé de figuration bien connu par la suite (les dieux plus grands que les hommes, v. 518-519) souligne peut-être l'appartenance à une autre discipline artistique que la poésie; mais surtout elle met au premier plan une présentation particulière de la relation entre hommes et dieux (ici marquée par une distance infranchissable), qui oblige à projeter un autre éclairage sur toute la vision du poème, en invitant à quelque scepticisme devant l'apparente familiarité régnant entre les uns et les autres tout au long de cette fiction héroïque qu'est superficiellement l'Iliade ${ }^{25}$.

Une modification d'un autre ordre mais non sans rapport avec la précédente intervient dans les vers suivants, avec la scène de l'embuscade (v. 520-534), qui semble cultiver un certain flottement. Car à y bien regarder cet engagement armé, auquel président les deux divinités guerrières les plus prestigieuses, a pour principal objet une lutte autour de troupeaux, dans des conditions qui sont loin d'être tout à fait claires. Certes il est souvent question de combats ayant pour enjeu des razzias de bétail, et l'on peut assurément lire ce texte au premier degré, comme relatant une simple échauffourée lors d'une expédition de ce genre ${ }^{26}$. Cependant quelques détails ont de quoi surprendre: l'insistance d'abord sur la localisation près d'un fleuve, dont la mention répétée aux vers 521 et 533 détermine entre le début et la fin

24 Tout en faisant place, chez les dieux, à un sentiment de condescendance qui souligne leur altérité : ainsi de XXI, 464-465, où un dieu en invite un autre à ne pas s'impliquer trop étroitement dans les affaires de ces humains aussi minuscules et interchangeables que des grains de sable ou des feuilles - idée dont la présente figuration (v. 517-519) fournit un équivalent plastique resplendissant. Pour le procédé de représentation qui consiste à figurer les dieux plus grands que les hommes sur les reliefs votifs (mais non sur les vases), $c f$. Fr. Lissarrague, Image et rituel: libation et sacrifice, in P. Demont, M. Perrin (éds), Actes du XXVI Congrès de l'Aplaes (Amiens, 1993), Amiens, 1994 , p. 44-52. C'est M. Paul Wathelet qui (dans un projet d'analyse formulaire du Bouclier d'Achille) a attiré mon attention sur la disparité entre cette image et l'antagonisme d'Arès et d'Athéna dans le reste du poème : je tiens à l'en remercier.

25 Il existe en effet un contraste entre tous les traits proprement épiques qui émaillent l'Iliade, et le manque total, sur le Bouclier, de l'idéologie héroïque, de la vie partagée des dieux et des héros qui constitue la pure substance de l'épopée : $c f$. Di Donato (supra, n. 6): p. 252.

26 Cf. F. Robert, Homère, Paris, 1950, p. 179-180. Cette remarque vaut pour la plupart des détails qui vont être relevés : tout ce passage nous semble avoir un double sens, chaque circonstance pouvant s'expliquer dans le contexte simple des troupeaux qu'on guette au moment et à l'endroit où ils viennent s'abreuver, mals pouvant aussi se laisser lire comme une image des combats guerriers (analogue à celle qu'on va retrouver un peu plus loin dans les vignettes pastorales : v. 575-586) puisque, comme le souligne Ch. R. Beye, The Iliad, the Odyssey and the Epic Tradition, New York, 1966, p. 144, les lions font partie des "common battle similes »; cf. infra, n. 29). De fait la polysémie (des images comme des termes) ne cesse de devenir plus dense au fil des scènes rurales, comme nous allons le voir p. $23 s q$. 
de cette brève séquence (v. 520-534) un autre effet de composition annulaire interne; elle est d'autant plus sensible que le décor champêtre du fleuve forme les deux fois contraste avec les mentions concomitantes du bronze des armes (v. 522 et 534), ce qui produit comme une superposition obstinée du monde pacifique de la nature à celui de la violence guerrière ${ }^{27}$. Ensuite la curieuse succession de changements de sujets (ol $\delta \dot{\epsilon}$ trois fois entre les vers 520 et 530 , dont une, v. 525 , pour représenter les bêtes, avec l'insertion au v. 527 d'un of $\mu \epsilon^{\prime} \nu$ ) engendre un léger effet de confusion, comme s'il fallait mélanger non seulement l'un et l'autre camp, les hommes en armes, tendus, et les pasteurs désarmés, insouciants, mais encore groupes humains et troupeaux $^{28}$. De tout cela il résulte que le passage semble suggérer l'indifférenciation du combat et des deux camps, et prépare de plus l'emploi ultérieur de l'imagerie animale pour évoquer la bataille. Cette substitution d'acteurs animaux aux belligérants humains nous semble en effet chose accomplie un peu plus loin dans les vignettes pastorales qui selon nous terminent la mise en abyme diégétique et narrative de l'Iliade sur le Bouclier ${ }^{29}$. En tout cas, pour ce qui est des correspondances thématiques entre les scènes dont nous venons de parler et le sujet de l'œuvre entière, on voit qu'elles ne sont pas de simples reprises pour ainsi dire plates, mais qu'elles indiquent un glissement de point de vue : plus les termes et les thèmes sont identiques, mieux on aperçoit le décalage introduit entre l'œuvre du dieu (qui a tendance à brouiller attaquants et attaqués, hommes et bêtes), et celle du poète (qui

27 Ce contraste parcourt toute l'Iliade, dans laquelle l'importance des fleuves de Troie n'est plus à souligner : $c f$. D. BOUviER, La tempête de la guerre. Remarques sur l'beure et le lieu du combat dans l'Iliade (infra, Tempête), in Mètis, 1 [1986], p. 237-257, spéc. p. $252 \mathrm{sq}$. Rappelons également la mention qui est faite à deux reprises dès le chant II (v. $861 \& 875)$ « du » fleuve auprès duquel Achille abattra des Troyens ( $c f$. D. Aubriot, Non-paysage, para-paysage et anti-paysage dans l'Tliade, in M. Perrin (éd.), L'idée de paysage, Actes du Colloque d'Amiens, 1994, Greifswald, Reineke Verlag, 1997, p. 5-29, n. 11; cité infra, Paysage). Le même effet se retrouve un peu plus loin au v. 576 .

28 Bien entendu, tout devient clair à une lecture attentive; il n'empêche que la première impression laisse perplexe. Le commentaire d'Edwakds (supra, n. 9) fait observer implicitement cette confusion - en ajoutant même la remarque que le ol $\delta \epsilon ́$ du v. 525 pour les animaux est inattendu, puisque ßov̂s est d'ordinaire féminin; mais il n'en tire aucune conclusion (p. 220). De même dans Di Donato (supra, n. 6), p. 239. Ce souci que nous croyons lire en ces vers, de brouiller les camps, se laissait déjà apercevoir dans les deux comparaisons remarquables qui accompagnaient le retour d'Achille dans le monde de la guerre, au début du chant XVIII : d'abord semblable à une lueur s'élevant d'une île encerclée quand il s'avançait au bord du fossé (207-214), puis poussant un cri d'attaque quand il s'arrêtait sans aller plus avant (219-221), le fils de Thétis y était à la fois assiégé et assaillant, cumulant toutes les affres de la guerre.

29 V. 573-89; cf. infra p. 31-32. La correspondance entre la violence des animaux sauvages et celle des guerriers a été étudiée par Annie Schnapp-Gourbeillon, Lions, béros et masques. Les représentations de l'animal cbez Homère, Paris, 1981 (surtout p. 15-28; mais elle ne consacre aucun développement à ces scènes du Bouclier); et surtout par M. Clarke, Between Lions and Men: Images of the Hero in the Iliad, in GRBS, 36 (1995), p. $137-160$. 
s'emploie à proposer un récit circonstancié). Dans la distance considérable qui se trouve ainsi creusée, on ne saurait méconnaître que cette ëk $\phi \rho a \sigma l s$ (où triomphent anonymat, généralité, distance) place dans la perspective d'un ouvrage divin, plus encore qu'elle ne prétend « décrire » une œuvre d'art plastique.

Avant d'en venir à des scènes rurales d'une tonalité toute différente, on trouve pour ainsi dire l'apothéose du thème de la guerre dans quelques vers (535-540) où trois figures allégoriques du Combat (indiquant les phases successives d'un conflit : la Querelle initiale, le Tumulte de la mêlée, la Mort qui extermine) mènent une lutte d'une extrême violence, qui n'est pas sans rappeler (d'assez loin) le paroxysme des batailles sanglantes de XVII, 360-365. La brutalité de cette brève évocation des blessés ou des cadavres couverts de sang est telle qu'elle a semblé jurer avec le reste du texte homérique : les connotations "hésiodiques ${ }^{30}$ de ce passage en ont donc poussé certains à proposer l'expulsion de ces vers. Pourtant, ils laissent paraître une inversion de perpective bien dans le ton du Bouclier : en effet, ce sont ici les divinités qui sont comparées à « des mortels vivants» (expression saisissante!) ${ }^{31}$. Par ailleurs, à les considérer du point de vue qui est le nôtre, on est frappé au contraire par la précise congruité à l'action guerrière principale de l'Iliade, de ces personnifications divines de la lutte et du trépas «tirant » (v. $537:$ : દ̈ $\lambda \kappa \epsilon$ ) ou « traînant par les pieds » (v. 540 : Épvov) les corps blessés ou morts de leurs mutuelles victimes ${ }^{32}$. Comment ne pas y voir rappel ou annonce des deux

30 En raison précisément des évocations brutales qu'il contient : la plus péremptoire à ce sujet est H.L. Lorimer, qui affirme que Ker constitue « an unmistakable example » de tranfert direct depuis le Bouclier d'Hésiode (Stars and Constellations in Homer and Hesiod, in $A B S A, 46$ [1951], p. 86-101, spéc. p. 93). On trouvera une excellente mise au point sur toute cette question dans TAPLIN, 1980 (supra, n. 1), p. 12 sq., avec la bibliographie : F. Solmsen, Ilias $\Sigma$ 535-40, in Hermes, 93 (1965), p. 1-6; GärTNer (supra, n. 9), p. 59; J.M. LYNN-GEORGE, The Relationship of $\Sigma$ 535-40 and Scutum 156-60 re-examined, in Hermes 106 (1978), p. 396-405; mais il faut signaler, contra, M. VAN DER VALK, Le Bouclier du Pseudo-Hésiode, in REG, 79 (1966), p. 449-480); W.G. Thalmann, Conventions of Form and Thought in Early Greek Epic Poetry, Baltimore, 1984, p. 62-64. En tout cas, on célèbre à l'envi le caractère idyllique des scènes du Bouclier d'Achille ( $c f$. le commentaire d'EDwards, p. 220 pour l'interpolation acceptée, et 224 pour le caractère idyllique), que ce soit pour les trouver déplacées, ou pour en faire un cadre général propre à former contraste avec les scènes guerrières (TAPLin, Homeric Soundings, p. 204-205; R. BuxtoN, La Grèce de l'imaginaire. Les contextes de la mytbologie, trad. fr., Paris, 1996, p. 96).

31 D'ordinaire, ce sont plutôt les hommes qui sont comparés à des dieux; cette assimilation inversée a été analysée par Di Donato (supra, n. 6), p. 241. Nous avons déjà relevé un autre effet analogue (p. 16), et nous aurons l'occasion d'en apercevoir d'autres (infra, p. 28).

32 Le à $\lambda \lambda \eta \hat{\lambda} \lambda \omega \nu$ du v. 540, placé à la coupe, souligne bien la réciprocité des morts reçues et infligées. Cette espèce d'impartialité du combat et de la mort (thème promis à

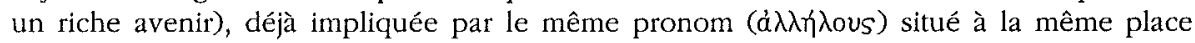
au v. 534, était affirmée d'un autre point de vue avec une brutalité sonore par Hector au

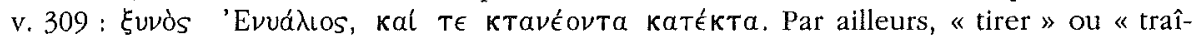
ner » un corps peut passer pour le comble d'une sauvage bestialité : les deux verbes ici 
morts (apparemment ici réunies de manière délibérée) qui s'enchaînent et se correspondent dans l'Iliade : celles de Patrocle et d'Hector ${ }^{33}$. Du premier, le cadavre est « tiré » à hue et à dia par les Troyens et les Achéens - et c'est alors surtout le verbe é $\rho u ́ \omega$ (ou é púopal) qui revient, toujours près de la coupe du vers (XVII, 127, 235, 277, 287, 396; cependant Ě $\lambda \kappa \omega$ se rencontre déjà aux v. 126, 393 et 395). Les outrages infligés au second, " traîné » comme on sait derrière le char d'Achille donnent lieu à l'emploi récurrent d'un verbe de la famille de "̈ $\lambda_{\kappa \omega}(X X I I, 336,398,401,464,465$; XXIII, 187; XXIV, 15). Cela mène à deux sortes de considérations. D'une part ce sizain, loin d'être une interpolation superfétatoire, se trouve bien à nos yeux intrinsèquement lié aux affrontements belliqueux qui scandent la trame du poème; en cela, il constitue une clôture parfaitement adaptée à la "mise en abyme » générale des combats sous Ilion offerte selon nous par l'évocation des deux villes. D'autre part il vient fournir une confirmation très nette, nous semble-t-il, de ce que nous avancions précédemment : il serait insuffisant de regarder ce passage comme une allusion aux seules batailles autour du corps de Patrocle ${ }^{34}$. Le texte acquiert une cohérence bien plus dense si l'on y discerne aussi un " écho anticipé », si l'on peut dire, des abominations qui vont accompagner la mort d'Hector. Il ne s'agit plus alors de souligner en passant de simples rencontres de mots. Si le rapprochement que nous proposons est valide, nous sommes en présence d'un procédé concerté par lequel les deux trépas qui sont liés dans le dessein de l'Iliade sont ici exhibés ensemble dans leur

considérés se retrouvent au chant XXII (v. 66 et 334-335) pour évoquer chiens ou oiseaux outrageant des cadavres.

33 Il est d'autant plus approprié de rapprocher ces deux fins qu'elles sont liées entre elles par un rapport de cause à conséquence (XVI, 851-854), et qu'elles sont expressément

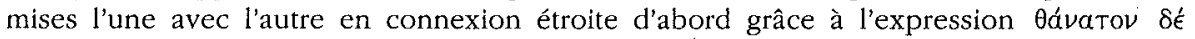

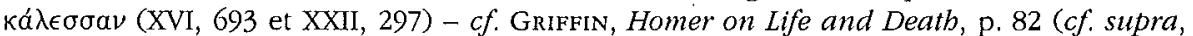
n. 22); M.H. Velasco-Lopez, Le vin, la mort et les Bienbeureux, in Kernos, 5 (1992), p. 20920, spéc. p. 211); puis grâce au même quatrain : "La mort qui tout achève déjà l'enve-

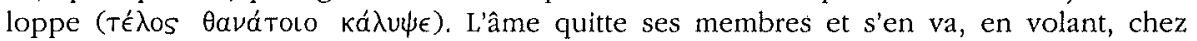
Hadès, pleurant sur son destin, quittant la force et la jeunesse. Il est déjà mort quand... ». De ces deux quatrains, l'un précède et l'autre suit notre passage à plus d'un millier de vers d'écart à chaque fois (XVI, 855-858 = XXII, 361-364). Aussi bien ce parallèle a-t-il été déjà souligné par Griffin, Homer on Life and Death, p. 42-3 (du point de vue du rapport de ces deux morts à la volonté divine); par Jacqueline De Romilly, L'bumanité d'Homère et les bumanités, in BAGB [1987], p. 150-164, spéc. p. 160, ou par Di BeNEDETto (supra,

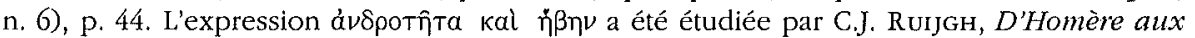
origines proto-mycéniennes de la tradition épique. Analyse dialectologique du langage bomérique, avec un excursus sur la création de l'alphabet grec, in J.P. CRIELAARD (éd.) Homeric Questions, Amsterdam, 1985, p. 1-96, spéc. p. 88-91. On pourrait ajouter une autre remarque, non dépourvue de conséquence: ces deux morts sont les seules pour lesquelles il soit parlé symétriquement de résurrection impossible (XXIV, 551 \& 756).

34 Comme cela a été aperçu à juste titre par ANDERsen, Thougbts (supra, n. 1), p. 11, après Walter Marg, Homer über die Dicbtung. Der Scbild des Achilleus, 2 Münster, 1971, p. 33, tandis que le rapprochement avec la mort d'Hector n'avait à notre connaissance guère été souligné. 
horreur nue, amplifiée, universalisée - tant par l'imagerie allégorique que par l'anonymat des combattants. De ces observations se dégage une puissante raison de considérer l'œuvre plastique du dieu comme une sorte d'équivalent de l'œuvre poétique de l'aède, mais considérée de plus loin et de plus haut, condensée en une focalisation extraordinaire qui superpose les acteurs, enjambe la succession temporelle du récit, et reflète même un point de vue inversé comme par un miroir.

\section{II ${ }^{\mathrm{e}}$ partie (v. 541-589) : la mise en abyme proprement nar- rative dans les scènes champêtres (" négatif photogra- phique » des comparaisons) ou la vie et la mort au-delà du miroir}

En effet à cette vision d'épouvante, à la fois colorée et générale (qui en quelque sorte nous met, hors de toute contingence et loin de tout personnage précis, en face de l'idée abstraite du combat, du carnage, de la mort), succèdent trois scènes en contraste patent avec ce qui les précède; chacune des trois est introduite - comme pour marquer la rupture - à l'aide d'un autre verbe à un autre temps, $\dot{\epsilon}^{\top}\{\hat{\imath} \in \mathrm{L}$. Elles représentent successivement (pour résumer la manière ordinaire de les considérer) le labour d'une jachère, la moisson d'un champ, la vendange d'un vignoble accompagnée d'un chant et d'une danse ${ }^{35}$. On comprend que cette énumération des travaux des champs ${ }^{36}$, succédant aux évocations de la ville en paix et de la ville en guerre, ait fait penser à un microcosme, « imago mundi » : pour saisir la raison d'être de ces scènes sur le Bouclier, on a voulu tantôt intégrer ces tableaux au reste des activités humaines représentées par le dieu; tantôt mettre l'accent sur la succession des saisons ${ }^{37}$, en retrouvant dans ces «vignettes » quelque chose des préoccupations « cosmiques » par lesquelles s'ouvrait la description. Ces interprétations - qui ne s'excluent pas - ne sont pas irrecevables. Mais même si le Bouclier est censé contenir un microcosme, l'Iliade avait-elle seulement

35 Chant et danse sont explicitement mentionnés aux v. 570-572. Peut-être faudrait-il interpréter la «coupe de doux vin » du v. 545 comme une allusion à une possible

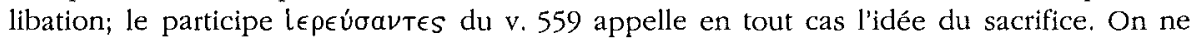
peut donc suivre tout à fait ANDERSEN - Tboughts (supra, n. 1), p. 8 - selon qui la vie religieuse est absente du Bouclier ( $c f$. infra, n, 64). On est obligé néanmoins d'observer à quel point les actes cultuels (s'ils sont évoqués, - et encore dans ce cas manquerait-il la prière) font seulement l'objet d'allusions discrètes. Les activités maritimes, quant à elles, manquent bel et bien (ce qui devrait faire réfléchir les tenants de l'interprétation des scènes du Bouclier comme un résumé des activités humaines).

36 Quoiqu'il manque les semailles, ce dont personne ne s'inquiète.

37 Encore qu'il manque l'hiver, à moins qu'on ne cherche, comme TAPLIN, Sbield (supra, n. 1), p. 9, à le trouver caché un peu plus loin, dans le vouós - devant lequel il s'avoue si perplexe qu'il se résoudrait à le croire interpolé; ou qu'on ne s'arrête à l'idée d'une division de l'année en trois périodes seulement ( $c f$. Cl. Calame, L'Hymne homérique à Déméter comme offrande: regard rétrospectif sur quelques catégories de l'antbropologie de la religion grecque, in Kernos, 10 [1997], p. 111-133, spéc. p. 123). 
des visées encyclopédiques ${ }^{38}$, et en quoi pareille énumération aurait-elle offert une valeur poétique exceptionnelle? Si ce que nous avons cru apercevoir pour la première partie (l'évocation des deux villes) a quelque fondement, il devrait exister un rapport entre ces vignettes agricoles et le reste du poème. Or ce rapport existe bien. Mais il ne s'établit plus avec le récit propre des péripéties qui adviennent autour d'Ilion. C'est cette fois ce que nous proposons de nommer le " contre-récit» formé par les comparaisons qui vient sans cesse à l'esprit quand on lit ces passages ${ }^{39}$ - qui offrent la particularité d'être dépourvus eux-mêmes de comparaisons.

Il est superflu de revenir ici sur la valeur poétique des comparaisons ${ }^{40}$. Mais outre leur premier effet qui est de tempérer l'émotion en éludant le pathétique primaire, elles aboutissent à assimiler la vie humaine à la vie végétale en faisant surgir des correspondances de divers ordres entre un trait humain et un élément de la nature ${ }^{41}$. Car, en dépit des évocations imagées, la nature n'y est pas donnée comme un spectacle : ce qui est saisi au fond de ces comparaisons, c'est la nature en action, en mouvement (vers la vie ou vers la mort), appréhendée de l'intérieur, à la source de ses «opérations » : il s'agit de l'identité du principe vital plutôt que de la ressemblance de ses occurrences particulières. En somme, le pittoresque disparaît derrière la

38 La question ne semble pas illégitime, même si des préoccupations taxinomiques sont sensibles ici ou là. Sur le savoir encyclopédique des poètes, $c f$. Françoise Bader, La langue des dieux ou l'bermétisme des poètes indo-européens, Pise, 1989, p. 17.

39 Cf. supra, n. 4. Certains de ces rapports ont déjà été relevés - TAPLin, Shield, (supra, n. 1), p. 14-15 -, sans que pour autant le poids de ces interférences ait été, semble-t-il, pleinement reconnu. La parenté de ces scènes agricoles du Bouclier avec les comparaisons peut s'établir également sur l'examen des traits de langue, comme veut bien me le préciser dans une lettre du 4 septembre $1996 \mathrm{M}$. Paul Wathelet, qui a mené par ailleurs un parallèle systématique fondé sur quelques expressions marquantes (Le bouclier d'Achille ou le pacifisme d'Homère, in Entretiens sur l'Antiquité gréco-romaine, Liège, 1995). Les rapprochements textuels qu'il souligne recoupent très largement nos constatations (quoique le point de vue général de l'A. soit plutôt historique tandis que le nôtre est plutôt littéraire et religieux). D'un autre côté, BEcker donne - 1995 (supra, n. 3), p. 49

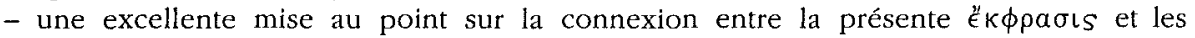
comparaisons, en la faisant porter sur trois points : le référent (contraste paix/guerre); l'effet (ralentissement de la narration); la technique (transcription des images en courtes histoires). Mais il ne s'occupe pas de sonder en quoi tout cela peut refléter une vision de la condition humaine. Cf. déjà S. LonSDale, Simile and Ekphrasis in Homer and Virgil, in Vergilius 36 (1990), p. 7-30; et, avec une application très générale mais une bibliographie intéressante, D.P. Fowler, Narrate and Describe: the Problem of Ekphrasis, JRS, 81 (1991), p. 25-35.

40 Elles ont donné lieu à plusieurs études, parmi lesquelles on retiendra P. Vivante, The Homeric Imagination. A Study of Homer's Poetic Perception of Reality, Bloomington London, 1970, p. 79 sq., C. Moulton, Similes in the Homeric Poems, Göttingen, 1977 (Hypomnemata, 49), et Annie BonnafÉ, Quelques remarques à propos des comparaisons bomériques de l'tliade: critères de classification et étude statistique, in RPh, 57 (1983), p. 79-97, spéc. p. 92.

41 Cf. Aubriot, Paysage (supra, n. 27), p. 13-14. 
«vibration » singulière qui donne vie à l'image et derrière le sens qui la justifie. Ces comparaisons, montre P. Vivante ${ }^{42}$ « conduisent vers un monde imaginaire où les objets apparaissent éloignés de leur place conventionnelle et situés, pour ainsi dire, dans une sphère de pure existence ». La suggestion d'ordre visuel, qui fait penser à l'amorce d'une description plastique, ne conduit pas à autre chose qu'à une sorte de paysage métaphorique, de «para-paysage ». Aussi n'est-il pas étonnant que le Bouclier se passe du recours poétique à ces sortes de comparaisons, pour une double raison : d'une part il en représente globalement pour ainsi dire un équivalent ${ }^{43}$; de l'autre il en décrit directement (donc sans plus recourir à la rhétorique de la comparaison) certains éléments.

Déjà la scène de labour ${ }^{44}$ évoque par des similitudes formelles saisissantes une comparaison du chant XIII, 703-707 où, pendant un rude combat, les Ajax étaient associés à « deux bœufs... qui, dans la jachère ('́v $\nu \epsilon \iota \hat{\text { a }}, \mathrm{XIII}$, 703, cf. XVIII, 541 et 547), tirent... la charrue... foncent sur la ligne du sillon;

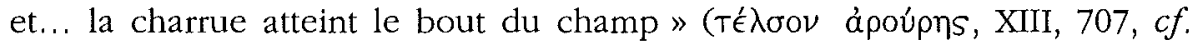
XVIII, 544, 547). Pareille similitude d'expressions ailleurs absentes de l'yliade a de quoi arrêter l'attention et suggérer que les efforts du labour avaient vocation à figurer ceux de la bataille où l'on peine. Mais la scène de moisson est peut-être la plus impressionnante. Relisons la description du Bouclier (XVIII, 550 sq.) : «Il y met encore un domaine ${ }^{45}$ royal. Des ouvriers moissonnent, la faucille tranchante en main. Des javelles tombent à terre

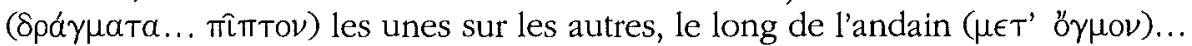
Parmi eux est le roi, silencieux, portant le sceptre; il est là, sur l'andain ( $\epsilon$ '

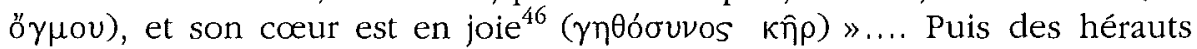
procèdent à un sacrifice tandis que les femmes préparent le repas ( $\delta \in \hat{\imath} \pi \nu$ T)

\footnotetext{
42 Vivante (supra, n, 40), p. 88.
}

43 Cf. supra, n. 39. J. Pigeaud a pu dire que le Bouclier est " l'absolu réalisé de la comparaison épique » (1988 [supra, n. 1], p. 59), après J. REDField qui parlait (supra, n. 1), p. 187, de «kind of master simile ». Cette expression se retrouve en substance dans EDWARDs, 1990 (supra, n. 1), p. 278, qui voit le Bouclier dans son entier comme « an enormous simile », et parce qu'il suspend le récit, et par son contenu; $c f$. encore Edwards, 1991 (supra, n. 9), p. 200.

44 À supposer que le labour seul soit en cause ( $c f . \mathrm{Cl}$. BÉRARD, Hersage, émottage, pilonnage, martelage, in F.E. KonNig, S. ReBeTez [éds], ARCULIANA, Recueil d'bommages offerts à Hans Bögli, Avenches, 1995, p. 607-617).

45 Il est impossible d'exploiter ici les réflexions que fait naître l'emploi des mots

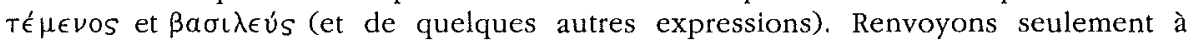
C. Moulton, Similes in the Iliad, in Hermes 102 (1974), p. 381-397, spéc. p. 390; à

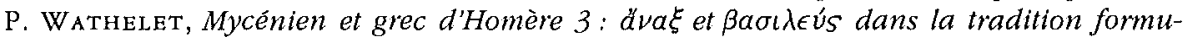
laire de l'épopée grecque, in ZA, 29 (1979), p. 25-40; cf. TAPLIN, Sbield (supra, n, 1), p. 20, n. 24; et ( $\beta a \sigma i \lambda \epsilon u ́ s$ au milieu), n. 34. On pourrait faire observer que d'ordinaire se portent

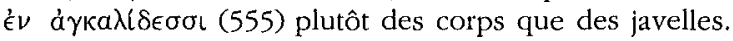

46 L'expression $\gamma \eta \theta$ ó un vers répété $(272=326)$, quand au chant IV Agamemnon passe en revue les rangs de

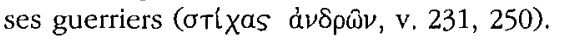


pour les moissonneurs, La première lecture de ce texte nous communique assurément un sentiment de géorgique heureuse, dans l'opulence de la richesse qui s'amasse. Mais les connotations prennent une autre teinte quand on se remémore un passage savamment orchestré du chant XI (v. 67 sq.). Les deux armées s'apprêtaient à reprendre le combat. Agamemnon venait de s'armer, et justement de revêtir son propre bouclier (v. 37, ce qui constitue une raison supplémentaire de rapprocher, en parallèle comme en contraste, les deux passages), où s'étalait le visage de la Gorgone ${ }^{47}$ entourée par Terreur et Déroute. Le récit du combat s'ouvrait cette fois (c'est plutôt rare) sur une comparaison : «Ainsi que des moissonneurs qui, face les uns aux autres, vont, en suivant l'andain (ö $\gamma \mu \mathrm{ov})$, à travers le champ... d'un bienheureux ${ }^{48}$, et font tomber dru les javelles ( $\delta \rho a ́ \gamma \mu \alpha \tau \alpha \ldots \pi(\pi T \in \mathrm{l}$ ), ainsi Troyens et Achéens, se ruant les uns sur les autres, cherchent à se massacrer... Éris, qu'accompagnent les sanglots, a plaisir à les contempler... Zeus s'est mis à l'écart et, assis loin des autres, dans l'orgueil de sa gloire ( $\gamma \eta \theta$ óouvos), il contemple à la fois la cité des Troyens et les nefs achéennes, et l'éclair du bronze, les hommes qui tuent, les hommes qui meurent. Aussi longtemps que dure l'aube et que grandit le jour sacré, les traits des deux

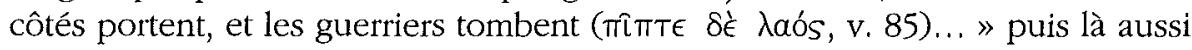
vient l'heure du repas ( $\delta \epsilon \hat{\imath} \pi \nu O \nu)$. Toutes ces rencontres d'expressions identiques font qu'il semble difficile de se figurer la scène de la moisson représentée sur le Bouclier sans se remémorer la comparaison du chant XI et sans en ressentir un certain malaise. Ces échos n'engageraient-ils pas à prendre ces rappels de comparaisons pour une incitation à effectuer le cheminement inverse de celui qui était impliqué dans le récit poétique? Tout comme l'évocation des travaux agricoles au fort de la bataille venait introduire dans la narration épique un contraste (pathétique mais reposant) au milieu d'une scène violente ${ }^{49}$, et détacher la mort au combat sur un fond de vie paisible, parallèlement la similitude des mots employés ici dans la description directe de scènes rurales pourrait avoir comme effet, au rebours, de rappeler (à la

47 Le bouclier de l'Atride se distingue de celui d'Achille à deux points de vue : d'abord ce qu'il représente est effrayant; ensuite la description s'attache à expliquer ce qui est sur les bords, ce qui 'est au centre, ce qui est clair, ce qui est sombre; en somme, c'est une vraie description, même si elle n'est pas dépourvue de sens symbolique (les différents boucliers décrits dans la poésie grecque sont passés en revue par Hardie (supra, n. 1), p. 13 sq.

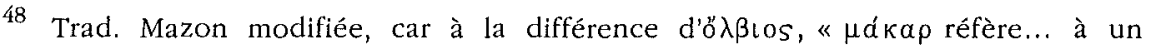
processus d'immortalisation »: CALAME, 1997 (supra, n. 37), p. 119. Certaines expressions parallèles (qui relient ces scènes à d'autres passages) ont été relevées aussi par D I Benedetro (supra, n. 6), p. 96-98. Le blé fauché (ou, en XIX, 222, la paille) a déjà été interprété comme une métaphore des corps des morts par WILLCocK (supra, n. 1), p. 219.

49 Ce rôle des comparaisons dans l'nliade a été bien mis en relief par D.H. Porter, Violent Juxtaposition in the Similes of the Iliad, in CJ, 68 (1972), p. 11-21 : cf. en partic. p. 19, où il est question des scènes décrites sur le Bouclier, en opposition avec les récits guerriers du poème. 
mémoire consciente ou inconsciente, mais de manière sensible) ce contexte de mort. Le résultat serait cette fois de rappeler dans le lointain l'âpreté des combats mortels à travers des scènes de vie. Au reste, dans la scène de moisson, le silence du roi ( $\sigma \omega \pi n \hat{~ a ̀ ~ l a ~ f i n ~ d u ~ v . ~ 555) ~ l a i s s e ~ p e r p l e x e ~}{ }^{50}$, et semble

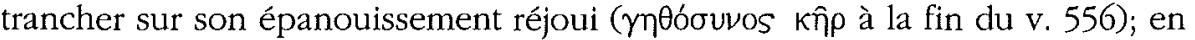
sorte que c'est finalement une impression mélangée qu'on garde, et que ce roi du Bouclier ne serait pas sans évoquer (même si c'est de très loin) un Zeus à l'impartialité distante, sinon un monarque infernal qui engrange les trépassés. Ainsi le langage poétique de cette ě $\kappa \phi \rho \alpha \sigma \iota s$ reprendrait, mais en sens inverse, celui de la narration; dans celle-ci, les scènes rafraîchissantes étaient introduites grâce à des comparaisons. Au centre du Bouclier au contraire la scène rustique fait l'objet propre de la description, et c'est la considération du passage antérieur qui suggère de lui superposer, comme en un théâtre d'ombres, ce qui allait devenir l'allégorie de la grande « Faucheuse ${ }^{51}$.

Ces probables connexions entre le labour et les pénibles efforts du combat, entre la moisson et la mort qui se propage quand les soldats sont «fauchés » par rangs entiers, engagent à chercher dans la même direction pour expliquer la scène des vendanges, quoiqu'elle ne réponde à aucune comparaison suivie. Les rapports sont là d'un autre ordre, plus ténus mais aussi, pour le nom même de ce qu'on traduit d'ordinaire par « vignoble ${ }^{52}$

50 Sur ce silence du roi, $c f$. Becker, 1995 (supra, n. 3), p. 132. Le silence en général a plutôt valeur négative: cf. Aubriot, 1992 (supra n. 18), p. 146 sq. Mais, surtout ici, quasiment en plein centre du Bouclier, ce silence ne marque-t-il pas une sorte de " trou noir " au milieu des évocations de danses et de chants qui scandent ce passage?

$51 C f$. par ex. les fresques de la chapelle de Kermaria-en-Isquit dans les Côtes d'Armor (qui date du xve s.), ou le poème «Mors », de Victor Hugo (Contemplations IV, 16). Comme a bien voulu me l'écrire le regretté Jules Labarbe (lettres du 23-XI et du 28XII-1996), on serait bien aise de pouvoir étayer cette perspective qui croit reconnaître au fil de l'Iliade « échos, parallèles et anticipations », sur " ce que pouvait apporter l'accompagnement musical (dont on parle peu quand il s'agit d'Homère); doit-on exclure que des espèces de leitmotive, égrénés sur la cithare, aient aidé le public à mémoriser un fait, un personnage, une image, et à les reconnaîttre en temps utile ? " Cette hypothèse tendrait à «prévenir les objections dues au fait que la performance orale devant un public d'auditeurs n'offrait pas les possibilités de rapprochement, de comparaison, de contrôle dont bénéficie plus tard le lecteur hellénistique ». Sans doute, concluait-il, en l'absence de témoignages « d'auteur ou de scholiaste sur les reprises et les réminiscences en musique ", doit-elle rester pour le moment une hypothèse.

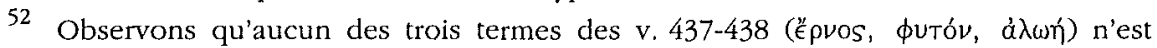
vraiment spécialisé pour la vigne ( $c f$. lettre de M. Paul Wathelet du 13-VIII-96, et voir A.D. URE, Thresbing-floor and Vineyard, in CQ, 49 [1955], p. 225-230). Selon Ileana CHIRAssiCоLомво, I doni di Demeter : mito e ideologia nella Grecia arcaica, in Studi Triestini di

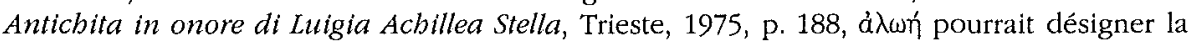
terre cultivée. Semblerait-il hasardé de faire valoir qu'une autre ả $\lambda \omega t$ devait être le lieu de capture de Lycaon (XXI, 36; 77, sur quoi cf. Margo KITTs, The Sacrifice of Lycaon, in Mètis, 7 [1992], p. 161-176, spéc. p. 164-165), une autre encore une aire de foulage où les guerriers avec leurs armes sont broyés pêle-mêle comme de l'orge (XX, 496-499); ou que Gorgy-

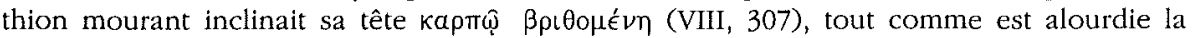


(ả $\left.\lambda \omega \eta^{\prime}\right)$, plus frais à la mémoire. En effet, en résumant pour lui la situation, Thétis vient de redire à Héphaïstos (comme elle l'avait fait pour les Néréides ses sœurs au v. 57) qu'Achille croissant " comme une jeune pousse au flanc

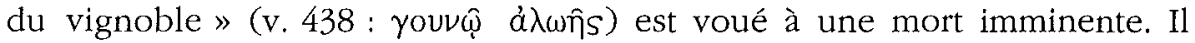
semble donc impossible de ne pas avoir cette expression présente à la pensée quand survient ici le mot ả $\lambda \omega n$. L'effet détonnant produit par la superposition d'une jeunesse pleine de sève et d'un trépas prématuré trouve à s'alimenter en plein coeur de la scène apparemment festive où un enfant s'accompagne de la cithare en chantant, tandis que jeunes gens et jeunes filles exécutent une danse. Il nous est en effet précisé que ce chant, émis d'un mince filet de voix, n'est rien d'autre qu'un Linos, que sa beauté n'empêche pas d'être comme on sait un chant de deuil aussi bien que de fête ${ }^{53}$. Quant au terme

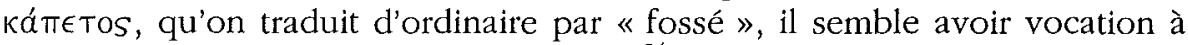
désigner dans l'yliade plutôt une «fosse ${ }^{54}$. En sorte que même si l'on hésite à faire valoir d'autres indices peut-être discutables quoique concordants ${ }^{55}$, on

vigne par les grappes ( $\beta \rho(\theta o v \sigma a v$, v. 561)? Achille, Lycaon, Gorgythion peuvent passer pour des symboles de la jeunesse «vendangée » en pleine sève, et тpưáw semble avoir été employé pour le travail du pressoir (D.E., s.v. Tpúk). Il se pourrait donc que soient rassemblées ici avec ces trois noms toutes les phases de la vie d'une plante cultivée, de la croissance à l'écrasement.

53 Cf. PIND., fr. 128 c Snell-Maehler; HDT., II, 79. C'est la seule occurrence de l'Iliade où ce mot désigne un chant. Ailleurs, c'est un tissu, ou un fil - et deux fois le fil de la destinée d'Achille (XX, 128; XXIV, 210), coïncidence qu'on aurait peine à trouver indifférente. Sur la triple étymologie du mot linos, cf. D. ARnould, Le rire et les larmes dans la littérature grecque, Paris, 1990, p. 220. Les structures similaires des chants de mariage et des chants funéraires ont retenu l'attention de S. Lonsdale, Dance and Ritual Play in Greek Religion, Baltimore, 1993, p. 236 sq., en rapport avec ce passage. Cf. Margaret Alexiou, The Ritual Lament in Greek Tradition, Cambridge, 1974, p. 57-58.

54 Angeliki Petropoulou, The Interment of Patroklos, in AJPh, 109 (1988), p. 482-495, spéc. p. 489-490.

55 On est frappé par la concentration dans ces quelques vers, de termes rares. Il n'y a pas dans l'Iliade d'autres "porteurs " ( $\phi \circ \rho \hat{\emptyset} \epsilon s, 566)$ que ceux-ci, et le mot est demeuré inhabituel (cf. J.L. Perpillov, Les substantifs en $\epsilon u ́ s$, Paris, 1973, p. 82; 347 sq.); le serait-il autant s'il avait désigné une activité aussi triviale que le radical semble l'indiquer? Et

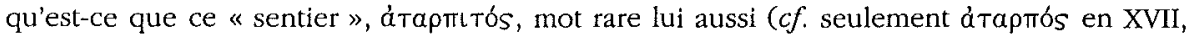
743) et hapax dans l'lliade, dont la seule chose que nous dise le texte (mais avec quelle insistance !), c'est qu'il est unique ( $\mu$ la $\delta^{\prime}$ ol̆ $\eta$, 565) ? Si l'étymologie de ce terme ne semble pas en faveur du sens de " raccourci », " chemin qui ne tourne pas » (D.E., s. v.), au moins son emploi ultérieur le plus célèbre (Pbédon 66 b) atteste-t-il son aptitude à être utilisé dans un sens figuré (observons chez Platon sa juxtaposition à l'infinitif $\epsilon ́ \kappa \phi o ́ \rho \epsilon \iota \nu$, et l'affirmation un peu plus loin, 66e, que semblable chemin vers la vérité ne pourra être véritablement suivi qu'après la mort). En sorte que si rien ne l'exige, rien ne s'oppose non plus à une compréhension métaphorique de ce chemin, emprunté par les " porteurs » de raisin vendangé ou foulé (si le rapport à toatté() peut être accepté), vers le «fossé » (ou la fosse - sombre!) entouré de « l'enclos». Si l'on ajoute que les danseurs " suivent » avec des battements de pieds, au son de cris capables d'exprimer la douleur $(l v \gamma \mu \hat{\omega}, 572 ; c f . D . E ., s . v . l u ́ \zeta \omega)$, on acceptera que ces notations, jointes aux autres, puissent paraître constituer un ensemble pour le moins ambigu, évoquant un contexte où 
reste cependant sensible à une certaine tonalité funèbre qui sourd à travers la réjouissance. On est d'autant moins enclin à s'abandonner sans réserve au seul plaisir de la fête, que les mentions de couleurs des vers 562-4 font la part large aux tons sombres, avec le noir des raisins et le fossé kvavénv. Or, si la description a été jusqu'ici relativement avare en notations chromatiques (hormis le rouge du sang au v. 538), on remarque cependant que le contraste formé par le vignoble en or et les raisins noirs qui y sont attachés ( $\chi \rho v \sigma \epsilon i ́ \eta v$ et $\mu \epsilon^{\prime} \lambda a \nu \in S$ de part et d'autre de la coupe du v. 562) vient redoubler sur le mode statique celui qui, doublé d'une indication dynamique, suscitait aux vers 548549 l'admiration du poète, en ce que justement « la terre allait noircissant derrière la charrue, quoiqu'elle fût en or ${ }^{56}$. En cette sorte d'oxymore figuré par la transmutation de l'or en noir réside justement le comble de la merveille. Puisque l'or va de pair avec la divinité (ainsi qu'en fait foi l'insistance du vers $517^{57}$ ) et le noir avec le deuil, on soupçonne qu'on n'a pas tort d'éprouver des sentiments partagés devant cette scène de vendange - ou de foulage ${ }^{58}$, et que la mort sombre y côtoie sans doute l'immortalité dorée.

Plusieurs raisons se conjuguent donc pour inciter à deviner dans ces trois vignettes des allusions au dur combat, au trépas qui en résulte, voire aux cérémonies qui accompagnent les funérailles. On ne saurait dire qu'elles occultent l'impression dominante d'abondance féconde, de vie paisible et rustique. Mais elles lui donnent une autre dimension en dessinant les contours de la vie sur un fond de mort omniprésente : percevoir cette dimension amène à confirmer le rôle sobrement pathétique des comparaisons ${ }^{59}$ dans l'lliade, en reconnaissant ici l'effet de symétrie. Le Bouclier, lui, ne comporte

le deuil le dispute à la joie : cet « enclos » ne serait-il pas d'un genre très particulier, et ce «chemin » ne mènerait-il pas vers une fosse funéraire ? Car de quel usage serait un vulgaire fossé dans une scène toute simple de vendange et de foulage du raisin?

56 Ce qui précisément constituait le comble de la merveille ( $\theta a \hat{\mu} \mu a)$ : cf. infra (p. 28).

57 Cf. supra, p. 16.

58 Cf. supra, n. 52. Pour les affinités des couleurs sombres avec le deuil, souvenonsnous par ex. d'H.H. Dém. 320; 361; 375; 443; voir aussi P. VIDAL-NAQUET, Le chasseur noir, Paris, 1981, p. 164. Outre la juxtaposition de l'or et de la couleur noire, il existe un autre lien entre la vignette du vignoble et celle de la jachère : le $\delta$ Émas $\mu \epsilon \lambda \iota \eta \delta E ́ o s$ olvou pro-

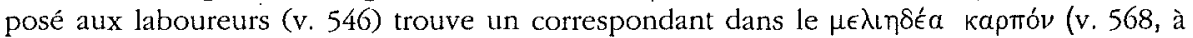
la même place) apporté dans des corbeilles tressées - autre indice de la cohérence interne de ces scènes agricoles.

59 Que les comparaisons liées à la vie entretiennent un rapport nécessaire et spécifique à la poésie de l'lliade reçoit une sorte de confirmation dans le nombre relativement réduit de celles qu'on trouve dans l'Odyssée. Ce procédé poétique saillant, propre à souligner un moment d'émotion culminant, a donné lieu à mainte étude. Cf. supra, n. 40, à quoi il faut ajouter CLARKE (supra, n. 29), qui dégage leur importance essentielle pour faire saisir la bestialité d'un héros en action. Le caractère récent des comparaisons avait déjà été avancé par T.W.L. WeBster, Early and Late in Homeric Diction, in Eranos, 54 (1956), p. 34-48, et Edwards y voit la marque de la vision et de la pensée personnelles du poète : 1990 (supra, n. 1), p. 103. 
guère de comparaisons ${ }^{60}$ - sauf une, à la fin, d'autre nature, avec le monde de l'art $^{61}$, sur laquelle nous reviendrons. Mais il possède en son centre, dans une description directe, ce qui dans le reste du poème forme la matière principale des comparaisons. Tout se passe donc comme si mouvement et sens des réalités de la vie et de la mort étaient inversés, en même temps que la texture du récit est interchangée : on pourrait dire que ces trois scènes de travaux des champs, qui visiblement forment un ensemble homogène dans sa complémentarité interne (comme le montre le triple ét $t(\theta \epsilon \iota)$, sont là pour renvoyer la vie à la mort dans un rapport - muet mais sensible - à ce que par ailleurs le poème laisse apercevoir dans le lointain, à travers le prisme des comparaisons. Ici, outre que le point de vue est renversé, puisque la mort se laisse deviner à travers l'évocation de la vie et non l'inverse, la perspective encore est entièrement modifiée, puisqu'il n'y a pas deux modes de narration explicitement enchaînés (le récit et les comparaisons), mais que les scènes empruntées au monde des comparaisons sont juxtaposées, sur le même plan, à la diégèse en abyme des péripéties survenant autour d'Ilion. La connotation équivoque de l'exécution musicale qui clôt cet ensemble reflète bien l'ambiguilté de cette présentation.

En même temps ces figurations produisent un autre effet, qui est d'attirer l'attention sur un mode d'expression particulier au dieu forgeron, touchant proprement à la nature des choses. Il consiste à ciseler dans le métal incorruptible des chairs «semblables » aux chairs vivantes ${ }^{62}$, quoique resplendissantes, c'est-à-dire quasiment immortelles - transposition trop glorieuse de la fragilité du vivant; si bien que là encore, puisque c'est le vivant périssable qui sert ici de référence, est dessinée en une sorte de relief en creux la figure inversée de la matière du récit. Cette «merveille » est explicitement suggérée au vers 549, par le mot $\theta a \hat{u} \mu \alpha, \theta a u ̂ \mu \alpha$ seul, remarquera-t-on - et non pas $\theta a \hat{\mu} \mu \alpha$

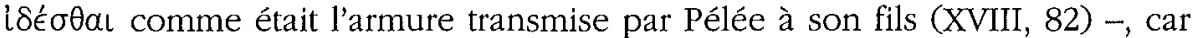
justement pour une fois la merveille n'est pas à voir ${ }^{63}$, mais à concevoir. En un rapprochement symbolique éloquent, l'or du dieu ne préserve pas la terre des hommes, qu'il figure, d'« aller noircissant ». On aurait donc affaire à une sorte d'« iconocryptie », si l'on peut ainsi s'exprimer, où l'image de la mort se laisse entrevoir à travers l'art divin figurant la vie ${ }^{64}-$ ce qui vient approfondir

60 Cf. supra, p. 23

61 V. 600-601: cf. infra, p. 43-44.

$62 C f$. le v. 548, où l'on observe la même inversion de point de vue : cf. supra, p. 19.

63 Cf. R.A. PRIET, Thauma Idestbai: The Pbenomenology of Sigbt and Appearance in Archaic Greek, The Florida State University Press, 1989.

64 Peut-être n'est-il pas indifférent que cet ensemble formé par les trois vignettes agricoles soit précisément le passage qui renferme une possible allusion à tous les gestes cultuels (hormis les actes de parole) propres à relier le monde des vivants à celui des dieux ou des morts : à la libation et au sacrifice (cf. supra, n. 35) il faut ajouter l'offrande funéraire de gruau ( $\lambda \in u^{\prime} k^{\prime}$ ă $\lambda \phi i t a$, en 560 comme en $O d$. X, 520 et XI, 28 : $c f$. STANLEY (supra, n. 1), p. 310, n. 36; faute de songer à cette interprétation, on s'expose à quelques 
encore le champ de vision : ce ne sont plus seulement les péripéties de la vie humaine qui sont considérées avec détachement; c'est ici le rapport de la vie à la mort qui est aperçu pour ainsi dire «sub specie æeternitatis », comme il convient à la perception d'un dieu.

Ces trois scènes agricoles sont suivies de deux vignettes pastorales de longueur très inégale, qui tout en formant (par leur sujet champêtre) la suite évidente des trois précédentes, tranchent néanmoins sur elles, à la fois par le verbe qui les introduit et par son temps (l'aoriste noĺnбe sans augment après les imparfaits $\left.{ }^{65}\right)$. Le fait que ces deux vignettes concernent apparemment des animaux, leur présentation au moyen de la même forme verbale, sont des éléments qui les unissent indéniablement l'une à l'autre. Pourtant, on ne saurait les considérer comme strictement parallèles entre elles, ne serait-ce qu'en raison de leur disproportion; de plus d'autres considérations s'ajoutent, qui laissent apercevoir une sensible différence de texture entre l'une et l'autre. Enfin comme nous le verrons, une étroite concaténation les unit à la vignette suivante, du $\chi \chi^{0}$ ó $^{66}$. C'est dire qu'il va falloir tenir compte de cette double particularité : tout en entretenant des relations certaines avec les trois scènes agricoles qui les précèdent, ces deux vignettes pastorales s'en distinguent nettement, et semblent tournées aussi bien vers la dernière scène ouvrée par le dieu.

La première de ces vignettes, qui comprend quatorze vers (573-586), se présente d'une manière tout à fait originale par rapport à tout ce qui la précède, en ce qu'elle mélange des éléments empruntés aux deux claviers, du récit et du contre-récit. Elle figure un troupeau de vaches ${ }^{67}$ se rendant au

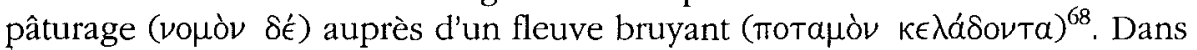
ce tableau bucolique on observe un retour à des allusions assez transparentes aux péripéties narrées par le poète, intimement fondues avec des expressions qui évoquent plutôt des comparaisons : ainsi de la scène des bergers excitant leurs chiens contre deux lions qui surviennent, «traînent »

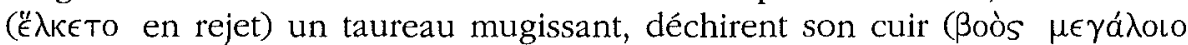

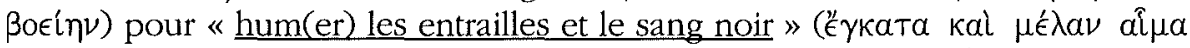
$\lambda a \phi u ́ \sigma \sigma \epsilon T \mathrm{\nu})$. C'est cette fois tout un écheveau de passages divers qu'il faut

difficultés culinaires : $c f$. Edwards, 1991 (supra, n. 9), p. 224. Mais tout cela demeure naturellement au second plan, derrière le chant funèbre et la danse (v. 569-572).

ós Nous ne pouvons pas ici nous attarder comme il conviendrait sur les conséquences pour le Bouclier de l'étude de. L. BAsset, L'augment et la distinction discours/récit dans l'lliade et l'Odyssée, in Études bomériques, Lyon, 1989 (TMO, 17), p. 9-16. Mais sans prétendre sonder les nuances, on peut signaler l'extrême subtilité de l'emploi qui est fait des verbes, de leurs temps, de l'usage de l'augment.

${ }^{66}$ Cf. Di Donato (supra, n. 6), p. 250.

67 Elles aussi semblent avoir une nature mêlée, puisqu'elles sont faites d'or et d'étain (v. 574).

68 Ce vers est regardé par certains comme le plus beau de l'rliade : Di Donato (supra, n. 6), p. 249. 
rassembler pour faire saisir la richesse des harmoniques dont retentit ce texte. Nous pourrions laisser de côté le verbe $\ddot{E} \lambda \kappa \omega$ dont nous avons déjà relevé la résonance avec les deux morts de Patrocle et d'Hector ${ }^{69}$, si le cuir déchiré du taureau n'évoquait une comparaison du chant XVII ${ }^{70}$, juste au moment où Troyens et Achéens s'arrachent le plus brutalement le corps du compagnon d'Achille: «On voit parfois un homme donner à tendre à ses gens le cuir

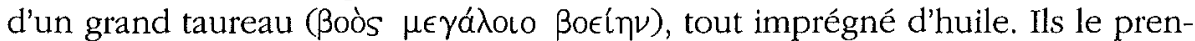
nent et s'écartent, en faisant cercle pour le tendre... l'huile pénètre d'autant mieux qu'il y a plus d'hommes à tirer $(\hat{\epsilon} \lambda \kappa o ́ v \tau \omega \nu)$... C'est ainsi qu'en un étroit espace les deux partis tirent ( $\epsilon[\lambda \kappa \epsilon o \nu)$ le mort... Tous au cœur ont bon espoir, les Troyens de le traîner ( $\epsilon \rho v ́ \in t \nu$ ) jusqu'à Troie, les Achéens jusqu'aux nefs creuses ». Cette nouvelle similitude (entre un passage appartenant au reste du poème et un passage du Bouclier) vient confirmer à quel point était fondé notre rapprochement entre les deux premières scènes géorgiques et les comparaisons de l'épopée, et combien l'épisode de la mort de Patrocle semble décidément affleurer souvent dans ces scènes du Bouclier. Mais on peut aller plus loin: il n'est pas jusqu'aux deux lions cruels qui ne trouvent leur répondant exact dans le " contre-récit » du poète - dont en retour ils aident à saisir le savant ajustage. Deux textes se présentent en effet en écho à cette vignette du Bouclier, deux comparaisons distinctes qui concernent successivement chacun des deux Atrides. L'un d'eux renvoie encore à cette bataille farouche autour du corps du fils de Ménœtios : en le défendant, Ménélas avait tué Euphorbe ${ }^{71}$ qu'il voulait dépouiller. L'Atride était alors montré (XVII, $61 s q$.) tel un lion nourri dans les montagnes, qui a ravi la vache la plus belle et, « la prenant entre ses crocs puissants, lui (broie) d'abord le col, pour la déchirer ensuite et lui humer le sang et toutes les entrailles ( $a \mathfrak{i} \mu \alpha$ каا "̈ $\pi a ́ v T \alpha \lambda \alpha \phi u ́ \sigma \sigma \in \mathrm{L}$ ), tandis qu'autour de lui chiens et bergers vont poussant de grands cris - mais restent à distance et se refusent à l'affronter ». Tout comme l'évocation du festin sanglant (qui donne lieu à la répétition formelle soulignée à l'instant : "les entrailles et le sang », en chiasme, XVIII, 583, cf. XVII, 64), ce détail suggestif des chiens trouve son équivalent sur le Bouclier (583-586) : « Les bergers en vain les pourchassent (les deux lions) et excitent leurs chiens rapides : ceux-ci n'ont garde de mordre les lions; ils sont là, tout près, à aboyer contre eux, mais en les évitant ». On perçoit combien peut se justifier la mise en regard de cette comparaison avec la vignette du Bouclier,

69 Cf. supra, p. 19-20.

70 V. 389 sq. Cette traduction, comme c'est le cas presque partout ici, est empruntée (à quelques détails près) à $\mathrm{P}$. Mazon dans la CUF. Mais rappelons la belle traduction en vers blancs que Jules Labarbe avait donnée dans les Recueils de Textes d'bistoire publiés sous la dir. de Louis Gothier et Albert Troux, Liège, 1964, t. I, L'Antiquité, p. 117-121.

71 Euphorbe, autre exemple d'un «beau plant plein de sève » (XVII, 53-5) abattu prématurément. 
d'abord dans les mots employés (les entrailles, le sang ${ }^{72}$ ) et aussi dans le mouvement de l'image esquissée (les chiens prudents). Or le rapprochement, déjà remarquable, ne s'arrête pas là, et la correspondance avec le récit des combats est encore plus étroite : pour saisir la précision apportée par la présence de deux lions (au duel) il faut se rappeler encore quelques vers du chant XI qui montrent pour le coup Agamemnon lui aussi comparé, comme plus tard son frère Ménélas, à un lion; le fauve, cette fois, met des vaches en fuite, en saisit une, et « commence par lui broyer le col entre ses crocs

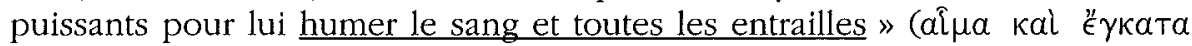

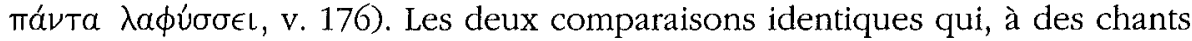
d'écart (de XI à XVII), faisaient saisir le parallèle entre la cruauté des deux Atrides, se trouvent rassemblées ici, de manière anonyme quoique

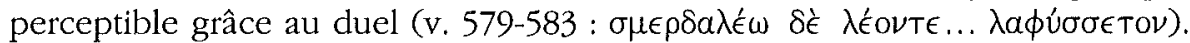
Cependant, sur le Bouclier, c'est un acte de sauvagerie purement animal ${ }^{73}$ qui est décrit, sans référence explicite ${ }^{74}$ au monde des guerriers : ce qui formait la matière de deux comparaisons pourrait bien là encore être passé directement dans la « description » de l'œuvre plastiqué, d'une manière qui cette fois amène non plus une inversion, mais une coïncidence entre le récit des « exploits » guerriers, et le monde des comparaisons ${ }^{75}$.

La vignette pastorale concernant les bovins se présente donc comme une réunion de deux procédés qui étaient d'abord apparus successivement sur le Bouclier : la reprise sur le mode général et anonyme d'une action en quelque

72 La subtile variatio sermonis distinguant l'expression qui revient dans les deux comparaisons et celle du Bouclier n'est pas sans signification : la jonction « les entrailles et le sang noir " a quelque chose d'effrayant et de grandiose (là encore de presque abstrait, car un sang frais n'est pas noir, ce qui paraît recommander un sens symbolique congruent à l'œuvre du dieu) tandis que l'alliance plus réaliste " le sang et toutes les entrailles » se borne à exprimer une avidité insatiable, assez dégoûtante. C'est à travers des détails comme celui-là qu'on saisit à quel point l'lliade forme un tout (à embrasser ensemble) dont l'ampleur n'empêche pas la subtilité (cf. supra, n. 22).

73 Et cependant repoussé dans le symbole et pour ainsi dire l'abstraction ( $c f$. la note précédente), mais il n'y a là aucune contradiction.

74 Encore remarque-t-on le verbe $\dot{\epsilon} \sigma \tau \iota \chi \chi^{\prime} \omega \nu \tau o$ au v. 577, qui n'est pas sans rappeler

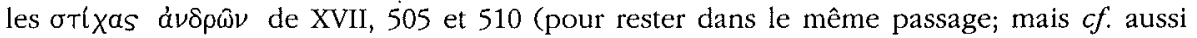
supra, n. 46).

75 Voilà en quoi il nous semble pouvoir parler ici (cf. supra, p. 18) de la substitution accomplie d'acteurs animaux à des belligérants humains, alors que la scène de l'embuscade près de la seconde ville n'en était qu'une amorce. La mise en parallèle de ces deux passages intérieurs au Bouclier est d'autant plus indiquée à nos yeux que des échos entre eux se laissent discerner - dont les plus nets sont peut-être la proximité d'un

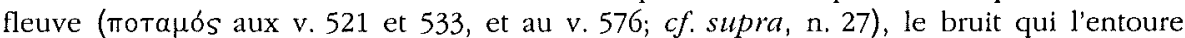

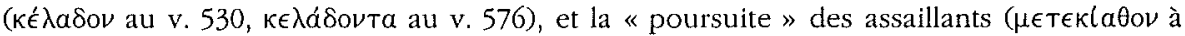
la même place des v. 532 et 581) - comme pour avertir qu'ils parlent de choses analogues. Notons en effet que ni $\kappa \epsilon ́ \lambda \alpha \delta o \nu$ ni $\mu \epsilon \tau \epsilon \kappa l \alpha \theta o \nu$ ne sont des mots d'un usage si fréquent dans l'Iliade que leur répétition ici ne soit frappante, puisque de chacun on ne trouve ailleurs que deux ou trois occurrences. 
sorte parallèle à celle des récits de l'Iliade (comme dans les v. 490-540); et le retournement de la matière des comparaisons en description directe, dynamique, de façon à faire passer au premier plan les réalités de la vie et de la nature, tout en laissant transparaître l'évocation de contextes où dominent les combats brutaux (comme en 541-572). Le tout produit un double effet, de surimpression et d'inversion. Avec ce troupeau de vaches férocement attaquées et mises en pièces on posséderait, utilisant le vocabulaire et la thématique des comparaisons (mais sur un mode beaucoup plus abstrait et, pourrait-on dire, lointain), un équivalent parfaitement résumé de la cruauté de la guerre, de l'impuissance des chefs, de la mort pitoyable des troupeaux guerriers sous la griffe et les dents des prédateurs - c'est-à-dire de la matière du récit propre de l'Iliade ${ }^{76}$. On parviendrait aussi à la substitution complète des bêtes aux hommes : ce ne sont plus des hommes qui sont comparés à des bêtes, mais (par-delà le procédé poétique de la comparaison, grâce à la fiction de la représentation directe du monde rural), ce sont des bêtes qui subissent le sort des hommes dans la boucherie du combat ${ }^{77}$. On assisterait donc à une sorte de reprise « latérale », si l'on peut dire, de la matière des v. 520-534, mais avec un degré d'éloignement supplémentaire. Il ne faudrait pas en effet se méprendre et accorder à cette confusion entre hommes et animaux une valeur pathétique excessive, encore moins peut-être y voir une réprobation morale devant ces ressemblances de comportement entre humains et bestiaux. Il se pourrait que l'assimilation ait plutôt valeur artistique, en suscitant un effet d'éloignement dans la généralité et dans la beauté : du point de vue du dieu, les comparaisons ne sont plus nécessaires. Au milieu d'un environnement naturel et végétal (fleuve bruyant, roseaux), hommes et animaux, à distance quasiment égale, voient les péripéties de leur vie et de leur mort aperçues dans un nimbe de splendeur dont l'éclat métallique magnifie le contraste avec la fragilité de la vie compromise, tout comme avec la vanité des efforts déployés pour la défendre.

Que faire, dans ces conditions, du pâturage de brebis (de faibles animaux, interchangeables, dont tout ce qu'on sait est qu'ils sont blancs, encore plus aisés à confondre que les vaches d'un troupeau) qui vient ensuite ? Il s'agit d'un couplet de trois vers (587-589), qui offre une originalité encore différente de celle qui marquait la vignette précédente : ce tercet représente de façon assez énigmatique un pacage apaisé, muet et apparemment immobile sinon vide de vivants (car si c'est « un pacage de brebis blanches », rien ne nous

76 Tout cela est nécessairement au conditionnel; mais ces quelques suggestions sont loin d'épuiser la richesse du texte, et maint autre rapport avec le reste de l'œuvre mériterait d'être souligné (par ex. nous laissons entièrement de côté tout ce qui concerne le symbolisme des métaux ou les nombres - portés ici au carré : $c f$. Françoise Bader, Bestiaire, onomastique, à paraître dans les Publications de l'Université de Franche-Comté, 1999, chap. III, section 8), dont l'examen orienterait dans le même sens.

77 Cela produit (par rapport au reste de l'épopée: $c f$. supra, n. 28) un effet d'inversion analogue à la permutation qui sur le Bouclier fait comparer l'œuvre divine à l'univers périssable des hommes (cf. supra, p. 28 \& infra, p. 41). 
indique ce qui leur arrive, ni même vraiment si elles y sont), lieu d'accueil semble-t-il idyllique, couvert et clos. Ces trois vers ont embarrassé tous ceux qui se sont donné la peine de s'y arrêter ${ }^{78}$, car leur caractère pour le moins elliptique étonne après la solennité avec laquelle ils sont présentés : c'est à

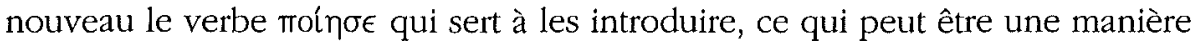
d'indiquer qu'ils relèvent encore de la " poésie », de l'invention épique (au même titre que les villes, et dans la suite du morceau consacré aux bovins); mais cette fois le sujet de cette forme verbale abstraite ${ }^{79}$ est exprimé, et de la façon la plus imposante qui soit, au moyen de la périphrase $\pi \epsilon \rho \iota k \lambda u T o ̀ s$ 'A $\mu \phi \imath \gamma v$ í $\epsilon$ เs, dont c'est le premier emploi, assurément significatif, dans tout le Bouclier, et qui occupe tout un hémistiche de ce très court tableau. C'est dire que la création en est rapportée à son auteur divin de manière presque emphatique. Cela impose de lui accorder plus d'importance qu'on ne le fait d'ordinaire. Il paraît en effet difficile de mettre ce petit tercet sur le même plan que les autres scènes rurales comme on s'y résout souvent, d'y voir un simple complément de la vignette pastorale immédiatement antécédente, sous le prétexte qu'il s'y agit de brebis après des vaches. Sa brièveté déjà en dissuade (qui tranche sur les séquences croissantes en longueur de $9+11+12+14$ vers qui précèdent, disproportion surtout sensible par rapport à l'autre tableau pastoral), ainsi que sa généralité vague, son caractère silencieux, presque inanimé (aucune présence humaine, aucun nom d'animal en fonction de sujet). Ce que représente «l'illustre Boiteux », ce sont (semble-t-

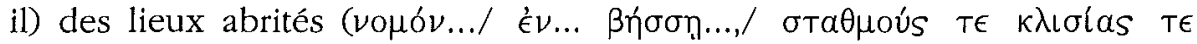

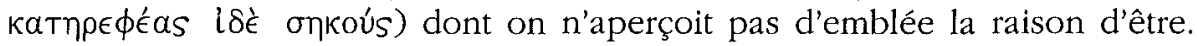
Serait-il pourtant concevable que ces trois vers - dans leur caractère mystérieux - soient sans rapport au reste du poème?

Deux ordres d'observations - qui s'entrecroisent - peuvent orienter la réflexion : d'une part le sens pour le moins ambigu de chacun des trois noms du dernier vers; de l'autre la place de cé petit couplet à la fin des scènes rurales, et son caractère au moins aussi problématique que celui de l'autre couplet ( le Trépas sanglant»), qui se trouvait situé à la fin de l'évocation des deux villes. Or estimer ces deux courtes séquences finales passibles d'explications parallèles et correspondantes se recommande d'une considération entraînée par ce qui précède: les deux sortes d'échos qu'il nous a semblé pouvoir dégager (surtout au récit des événements autour de Troie d'abord, avec les v. 490-540, puis surtout aux comparaisons dans les v. 54189), se succèdent selon deux masses à peu près équivalentes $(51 \mathrm{v},+49 \mathrm{v}$.) organisées en chiasme : a) $19 \mathrm{v} .+32 \mathrm{v}$. (i. e. v. 490-540 = la ville en paix + la ville en guerre); b) $32 \mathrm{v} .+17 \mathrm{v}$. (i.e. v. $541-589=$ les trois vignettes agricoles + les deux vignettes pastorales). Chacune de ces deux masses possède une

78 Ils ne sont pas légion. Mais $c f$. TAPlin, Sbield (supra, n. 1), p. 9. BeCker souligne énergiquement l'originalité de la présentation et du traitement de cet épisode, qui se détache de tous les autres (1995 [supra, n. 3], p. 141-142).

79 Cf. supra, n. 65. 
sorte de cohérence qui lui est propre. Il peut dès lors paraître légitime, s'agissant des derniers vers (le Trépas sanglant en 535-540, et le vouós en 587589) de ces deux ensembles équilibrés, de parler de clausules symétriques, et d'envisager un rapport entre elles - fût-ce à titre d'hypothèse de travail. Or cette hypothèse trouve à s'appuyer sur des indices tirés du vocabulaire du dernier vers.

Partons donc de ce vers 589 , sur lequel se termine la deuxième séquence

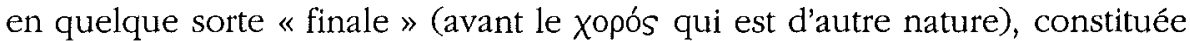
par le vouós. Il semble se caractériser par une polysémie possible de tous ses

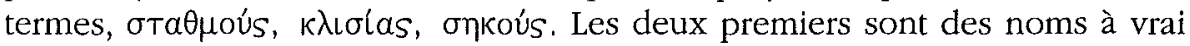
dire assez courants dans l'Iliade, surtout $\kappa \lambda$ roías. Ce mot, employé presque partout ailleurs (c'est-à-dire près de 120 fois!) dans cette épopée pour désigner les «baraques » des Achéens, pourrait inspirer sans trop de difficulté l'idée de reconnaître dans cet habitat un emblème des assiégeants d'Ilion. L'usage du nom $\sigma \tau a \theta \mu o u ́ s$ est plus varié, mais l'emploi fait de ce terme dans des contextes pastoraux en un certain nombre de passages du poème ${ }^{80}$ ne s'opposerait pas à la suggestion d'y voir un symbole des abris utilisés par les

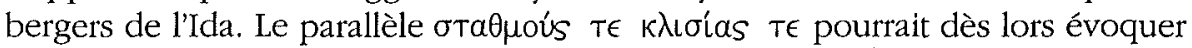
les asiles précaires des belligérants de part et d'autre. C'est une première possibilité. Cependant, il arrive que $\sigma \tau \alpha \theta \mu$ ós soit utilisé dans un contexte de fécondité, volontiers avec $\theta a ́ \lambda a \mu o s ~(X I V, 167,339)$ - à telle enseigne qu'on a cru pouvoir établir une relation entre $\sigma \tau \alpha \theta \mu o ́ s$ et le monde de la sexualité ${ }^{81}$. Cette considération rendra sensible, pour l'autre terme, aux arguments

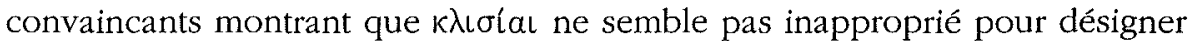
« la dernière demeure ${ }^{82}$; et l'on retiendra alors l'hypothèse d'une mise en forme allusive de la complémentarité entre les deux domaines de la fécondité ou de la vie, et de la mort, dont l'opposition parcourt toute l'Iliade; cette complémentarité - que tout désigne dans le poème (la thématique aussi bien que la poétique ${ }^{83}$ ) - se retrouverait ici sous une autre forme, purement spatiale et symbolique. C'est une deuxième possibilité, qui n'est pas incompatible avec la première. Quoi qu'il en soit, serait reprise une sorte d'allégorie des deux camps affrontés, réunis sous une même ambiguité entre hommes et animaux, mais de façon cette fois encore plus détournée, par le biais indirect

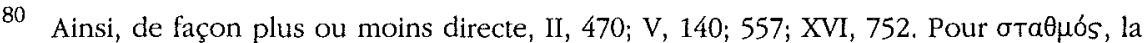
notion dominante semble être au moins celle de protection bien établie, tandis que

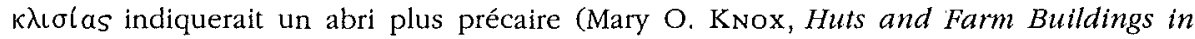
Homer, in CQ, 21 [1971], p. 27-31).

81 V.J. WонL, Standing by the Statbmos: Sexual Ideology in the Odyssey, in Aretbusa, 26 (1993), p. 19-50.

82 Petropoulou (supra, n. 54), p. 488-490.

83 Puisque l'opposition vie/mort, sous-jacente à tout le poème - voir Griffin, Homer on Life \& Death (supra, n. 22) - se retrouve dans le contraste quasi constant qui met en vis-à-vis les deux mondes, du récit et des comparaisons, autant que dans les oxymores commentés par P. Pucci, Ulysse Polutropos, Lectures intertextuelles de lTliade et de l'Odyssée (trad. J. Routier-Pucci), Lille (P.U. Septentrion), 1995, p. 215-217. 
des refuges. Cette postulation est peut-être moins hasardée qu'il n'y paraît; car l'assimilation des armées à des troupeaux ${ }^{84}$ était déjà, avons-nous vu, amorcée dans l'embuscade décrite aux v. 524-9, et reprise immédiatement avant, de manière plus nette, dans la vignette des bovins ${ }^{85}$. Elle apparaîtrait simplement dans ces deux vers dépouillée de tout contexte anecdotique et même animé, ce qui la porterait à un degré de généralité exceptionnel pouvant aller jusqu'à une simple opposition entre verticalité et horizontalité $^{86}$, en tout cas étranger à toute succession chronologique - comme il est normal sur une œuvre divine. Quant au nom onkoús, aussi propre à désigner les enclos du bétail que les enclos héroïques ${ }^{87}$, ne pourrait-il constituer une discrète invitation à deviner à travers ce court tableautin une allusion lointaine au séjour dans les îles des Bienheureux ${ }^{88}$ ? Peut-être est-ce solliciter beaucoup le texte ${ }^{89}$. Mais la polysémie des trois termes présente une cohérence interne assez saisissante pour qu'on en tienne compte.

84 Qui déjà nourrit l'imagerie d'un certain nombre de comparaisons ( $c f$. n. suiv.), qui de plus est soutenue par l'une des formules qui caractérisent (entre autres chefs)

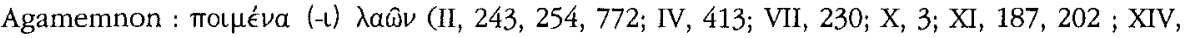
22 ; XIX, 35; XXIV, 654). Notons que le lien homérique entre les vocabulaires pastoral et politique se retrouve chez Platon ( $c f$. S. Bendrdete, The Plan of the Statesman, in Metis, 7 [1992], p. 25-47, spéc. p. 39).

85 Rappelons que les comparaisons animales n'apparaissent guère en dehors des contextes de combat : cf. Schnapp-Gourbeillon, 1981, p. 67, et Clarke (supra, n. 29 \& 59); ou encore S.H. Lonsdale, Creatures of Speech. Lion, Herding and Hunting Similes in the Iliad, Stuttgart, 1990 (non vidi).

86 On pourrait faire observer de surcroît que ces deux noms affichent, par leur étymologie, un contraste entre la position debout $\left(\sigma \tau a \theta^{-}\right)$, et la position couchée $\left(\kappa \lambda_{-}-\nu_{-}\right)$: l'expression $\sigma \tau a \theta \mu o u ́ s ~ T \epsilon ~ k \lambda \iota \sigma l a_{S} \tau \epsilon$ pourrait, en rapprochant verticalité et horizontalité, offrir un contraste symbolique de l'opposition vie/mort.

87 D.E., S.v.

88 De fait, le terme $\nu$ oús semble ici fondamental, en ce qu'il est proche du vocabulaire traditionnel de l'imagerie infernale $(\lambda \epsilon \iota \mu \omega \nu)$ et soutient la fiction pastorale, non sans la maintenir dans dés rapports ambigus avec la sphère politique ( $c f$. supra,

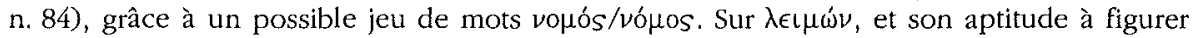
dans un contexte infernal, $c f$. A. Motте, Prairies et Jardins de la Grèce antique. De la Religion à la Philosopbie, Bruxelles, 1973, p. 239 sq. Soulignons qu'au v. 575, les vaches avaient été empêchées d'atteindre tranquillement le " pâturage " vers lequel elles se dirigeaient ( $($ ouòv $\delta \epsilon ́$ ) par l'agression des lions. Ici la perspective a changé, et c'est le vouós même qui est représenté.

89 Toutefois cette suggestion semble assez appropriée au contexte, qui fait à la mort une place si large. Elle offrirait en outre un double avantage : d'abord de proposer une explication pour un passage obscur, à la concision d'autant plus déconcertante qu'il est introduit avec solennité; ensuite d'éclairer la possibilité d'un rapport de fond entre le sizain du Trépas sanglant et le tercet du vouós, et ainsi de mieux saisir la « densité » ( $\pi u ́ k a$, v. 608) de ce tout savamment construit qu'est le Bouclier. En effet, il est irritant qu'en dépit de son importance de plus en plus reconnue, la vignette du vopós n'ait pas jusqu'ici reçu d'explication satisfaisante. Aussi n'est-il pas déplacé (au risque de s'exposer 
Si donc on pouvait dans ces trois vers apercevoir une sorte d'allégorie d'un séjour des défunts moins moisi et frissonnant que l'Hadès, le tercet du vouós et le sizain du Trépas sanglant auquel il répondrait mettraient en regard l'une de l'autre les deux faces de la mort, celle " qui tout achève ${ }^{90}$, et celle qui peut laisser place à une autre perspective. Or l'idée d'une semblable confrontation n'est pas sans répondant, puisqu'elle se trouve explicitement formulée dans Les Travaux et les Jours, quand Hésiode expose que, des « héros » qui perdirent la vie sous les murs de Troie, les uns connurent $t e ́ \lambda$ os $\theta$ avátolo, tandis que les autres devinrent habitants d'une contrée fortunée ${ }^{91}$. En somme, la place de ce tercet à la fin des scènes rurales, l'absence du moindre commencement d'anecdote (qui le distingue des autres tableaux), ainsi que l'espèce de porte-à-faux induit par l'apparente désinvolture de sa brièveté, disposeraient à ne pas l'aligner exactement sur le même plan que ce qui précède, mais plutôt à le prendre comme un couronnement des scènes rustiques (à la manière dont nous avons proposé de les comprendre), tout comme le couplet du Trépas sanglant venait clore en apothéose la représentation des villes. Il s'y oppose déjà comme le blanc au rouge ${ }^{92}$, le calme absolu à l'extrême violence. Mais le parallèle ne s'arrêterait pas là : cette clau-

au reproche de «surinterprétation » du texte) d'en proposer une, surtout si l'on se remé-

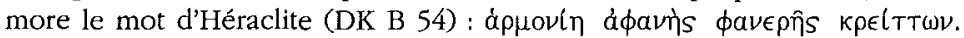

90 La quintessence du combat représentée dans les v. 535-540 se terminait par un carnage sanglant transformant les guerriers des deux camps ( $\dot{\alpha} \lambda \lambda \eta \hat{\jmath} \lambda \omega \nu$ ) en cadavres ( $c f$.

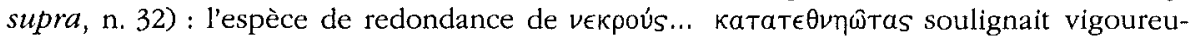
sement l'idée de mort irréversible ( $c f$. supra, n. 33) au dernier vers de ce passage. Dans l'évocation contenue dans les v. 587-9, l'idée de réciprocité a laissé place à celle d'alignement des deux partis sur le même plan ( $T \epsilon \ldots . T \epsilon$ ).

91 Hés., TJ, 173 sq. (À Troie) « la mort, qui tout achève, en enveloppa certains

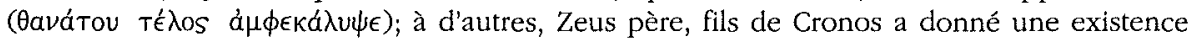
et une demeure éloignées des hommes, en les établissant aux confins de la terre ( $\dot{\epsilon} S$ $\pi \epsilon(\rho a \tau a$ yains). C'est là qu'ils habitent, le cour libre de soucis, dans les îles des

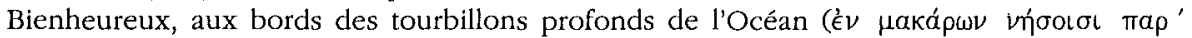
' $\Omega \kappa \epsilon a \nu o ̀ v ~ \beta a \theta v \delta(\nu \eta \eta \nu)$, héros fortunés, pour qui le sol fécond porte trois fois l'an une

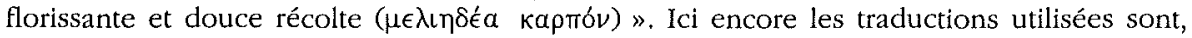
à quelques détails près, celles de la $C U F$. Sur ce passage d'Hés., $c f$. G. Broccis, Chi va ad abitare le Isole dei Beati?, in Euphrosyne, n.s. 10 (1980), p. 81-91; Fr. Sozmsen, Achilles on the Islands of the Blessed. Pindar vs. Homer and Hesiod, in AJPb, 103 (1982), p. 19-24, spéc. p. 22-23; J.-C. Carrì̀r, Mystique ou politique dans les Travaux et les Jours d'Hésiode. L'autbenticité et les enjeux. du vers 108, in Mélanges Étienne Bernand, ParisBesançon, 1991, p. 61-119, spéc. p. 97-99; Le mythe prométhéen, le mythe des races et l'émergence de la cité-État, in Fabienne Blaise, P. JUDET de LA COMBE et Ph. Rousseau (éds), Le métier du mythe. Lectures d'Hésiode, Lille (P.U. Septentrion), 1996, p. 393-429, spéc. p. $412 s q$. En tout cas, il n'est pas sans intérêt qu'on retrouve dans les vers d'Hésiode quelques expressions qui émaillent le texte homérique.

92 La seule notation de couleur indique en effet la blancheur. Souvenons-nous de la tradition (sommaires de Proclos, p. 106, 6-15 Allen) de l'Étbiopide qui attribuait à Achille un séjour immortel dans l'île Blanche du Pont-Euxin : $c f$. G. HedreEN, The Cult of Acbilles in the Euxine, in Hesperia 60 (1991), p. 313-330; Ph. Borgeaud, Note sur le Sépias. Mytbe et bistoire, in Kernos, 8 (1995), p. 23-29, spéc. p. 27-28. 
sule de trois vers prolongerait aussi la première sur un autre plan, qui était celui-là même du sizain, le plan de la mort.

Toutefois quand bien même ce lien, hypothétique, serait reçu pour établi, encore faudrait-il se garder d'y voir une incitation simple et positive (comme elle semble l'être chez Hésiode ${ }^{93}$ ) à considérer l'éventualité heureuse (dans certains cas favorisés) d'une mort moins définitive et désespérante que le trépas commun. Ce serait faire bon marché des conceptions générales de l'Iliade qui ne perd pas une occasion de souligner la misère humaine ${ }^{94}$. Il ne serait pas raisonnable de s'arrêter à la pensée que le poète, d'ordinaire si pessimiste relativement à la condition mortelle, puisse aller en adoucir la perspective par l'espérance, même parcimonieuse et conditionnelle, d'un audelà fortuné. Au reste, quelle pourrait être l'allusion à un héros particulier, et qui verrait-on dans l'Iliade, qui pût bénéficier de cette sorte de survie, puisque les deux grands morts que sont Patrocle et Hector connaissent, comme il est assez souligné, un trépas définitif, et que Sarpédon, le fils de Zeus, n'est pas épargné non plus par "la mort qui tout achève » TÉ OaváToto ${ }^{95}$ ? Quant à Achille (outre le fait qu'il ne meurt pas dans l'Iliade, ce qui interdit de considérer le poème comme une possible déploration sur sa geste) même sa mort, quand il en parle, est présentée par lui comme un terme absolu $^{96}$. Enfin, la situation de toutes les scènes du Bouclier sous un ciel

93 À supposer que ces vers n'y soient pas interpolés.

$94 C f$. en partic. le distique célèbre : « Rien n'est plus misérable que l'homme, entre tous les êtres qui respirent et qui marchent sur la terre ", Il. XVII, 446-447, repris dans $O d$. XVIII, 130-1. Sur ce pessimisme de l'épopée homérique, $c f$. Мотте, Prairies (cf. supra, n. 88), p. 251 sq.; Destin et destinée dans l'Antiquité, in A. GEsché (dir.), Destin, prédestination, destinée, Louvain, 1995, p. 51-72, spéc. p. 52-62. Tout en étant d'accord avec R.M. Rosen (Homer and Hesiod, in I. Morris \& B. Powell (éds), A New Companion to Homer, Leiden, 1997 [infra : New Companion], p. 463-488) pour reconnaître des interactions entre les deux poètes, je ne saurais adhérer à l'opinion selon laquelle Hésiode apporterait un correctif à un prétendu idéal iliadique d'héroïsme surhumain (p. 487-488), car il me semble justement que le poème entier de l'Iliade, tout en se conformant extérieurement à la tradition épique héroïque, en renverse la signification et jette le doute sur la valeur de cet idéal traditionnel.

95 Il. XVI, 502 (ce premier vers concernant la mort de Sarpédon la relie à celles de Patrocle et d'Hector). Dans le même sens de fin irréversible irait la redondance de XVI,

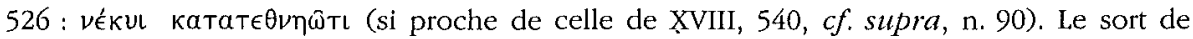
Sarpédon est d'autant plus révélateur, que le traitement de faveur dont il jouit aboutit seulement à lui faire octroyer des honneurs funèbres particuliers : son corps est bien soustrait miraculeusement du champ de bataille, mais pour être transporté en Lycie, où ses proches pourront l'enterrer "dans un tombeau, sous une stèle, puisque tel est l'hommage dû aux morts » (XVI, 674-675). On ne saurait mieux suggérer que le miracle s'arrête au tombeau.

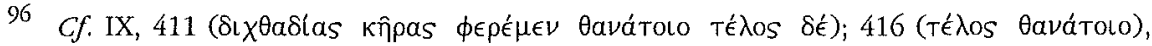
avec un chiasme frappant des deux mots, mais aussi la légère ambiguïté de la construc-

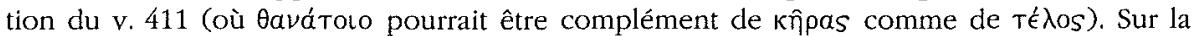
négation de l'immortalité dans l'Iliade, of. Scheis, The Mortal Hero (supra, n. 16), p. 48-49. 
$\mathrm{d}^{\prime}$ hiver ${ }^{97}$ ne laisse guère de place à une quelconque illusion d'embellie imaginable. Si donc il y avait, comme nous serions disposée à le croire, quelque pertinence à considérer ces deux couplets comme évoquant une distinction entre deux types de mort, encore faudrait-il bien mesurer sa signification dans l'Iliade en prenant en compte le caractère estompé de cette opposition et le mode pour le moins discret sur lequel elle est seulement suggérée. D'abord le face à face entre les deux couplets est inégal : avec un sizain d'un côté, un tercet de l'autre, la proportion se réduit du double au simple. Par ailleurs l'impression communiquée par ces trois derniers vers est plutôt celle d'un amuïssement ${ }^{98}$ étouffé (dans la beauté et le calme blanc, certes, mais quand même éloigné, silencieux et désert); et le détachement in extremis

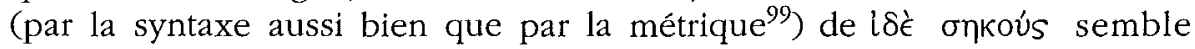
maintenir ce dernier mot comme en l'air, dans une suspension incertaine - ce qui n'est pas du tout en faveur d'une ouverture confiante vers l'héroïsation rituelle à laquelle peut faire penser le nom onkós lui-même. En conséquence, si ce texte devait être rapproché de celui d'Hésiode ${ }^{100}$, ce serait pour en souligner l'orientation divergente, le texte homérique étant trop ambigu ou allusif pour laisser entrevoir un véritable espoir en une forme quelconque de survie bienheureuse ${ }^{101}$. Il ne serait même pas impossible qu'il s'inscrive en faux contre une semblable idée. Le couplet du vouós formerait une transition parfaite entre l'espèce de reprise (de très loin et de très haut) de la relation des combats suggérée (en pleine abstraction) par la vignette des bovins, et l'ultime tableau qui parachève les représentations du Bouclier. Car la vignette du Xopós (avec son exécution orchestique et musicale) vient en quelque sorte prolonger en la corrigeant la séquence du Linos, et invite à reconsidérer le rôle de l'artiste pour illustrer le sens de la vie humaine. Il semble bien en effet que l'enjeu ne soit pas moindre que cela, même si nos formulations peuvent sonner comme anachroniques. C'est que l'impression « idyllique » communiquée par la lecture du Bouclier n'est, elle, pas une illusion : même si toutes les scènes champêtres peuvent se lire comme un négatif photographique des récits de combat et de mort elles n'en demeurent pas moins, dans une appréciation immédiate du texte, rafraîchissantes, voire jubilatoires - comme il est naturel dans l'optique d'un dieu « exempt de souci, toujours » (XXIV,

97 Cf. infra, n. 171.

98 On n'y trouve aucun être animé agissant; pas un seul article, démonstratif, présentatif qui puisse donner le moindre caractère précis à la scène; plus un bruit; plus un chiffre : la description s'exténue, comme si l'air se raréfiait.

99 Une coupe troisième trochaïque dégage l'adjectif $\kappa a т \eta \rho \epsilon \phi \epsilon ́ \alpha_{S}$, dont il faut bien penser que la signification est importante ici, puisque c'est un bapax dans l'Iliade, et que sa finale est allongée. Or l'allongement d'une brève au temps fort du cinquième pied est une licence métrique relativement rare, comme on le sait. Par ailleurs, la coordination

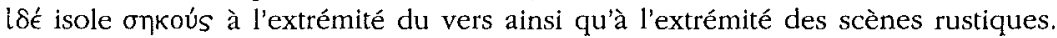

100 Sans vouloir préjuger de la difficile question de la possible antériorité de l'un sur l'autre.

101 Cf. Aubriot, Humanité et divinité dans liliade (supra, n. 5). 
526). Or cette opposition entre l'impression superficielle et l'arrière-plan qui est obstinément suggéré a besoin d'une explication. La clef de cette superposition antinomique entre les exploits guerriers narrés comme tels et leurs correspondants agrestes semble bien être donnée dans la dernière scène, que nous allons aborder à présent.

\section{II $^{\mathrm{e}}$ partie (v. 590-606) : le Xopós, l'artiste et le Cosmos}

Dès l'attaque du vers 590, deux points se conjuguent pour annoncer que ce passage va renfermer la quintessence de l'habileté du dieu en même temps que de sa vision distanciée. L'un réside dans la récurrence (à trois vers d'inter-

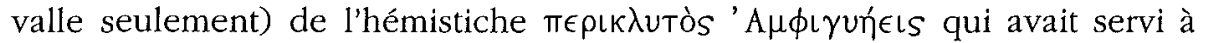
introduire le tercet du $\nu$ ouós : pareille répétition serait inconcevable si elle n'était commandée par une raison puissante. L'autre est constitué par l'emploi d'un verbe recherché (поíkı $\lambda \lambda \epsilon$ au v. 590) qui indique un travail d'artiste dont le caractère extraordinaire est marqué par cet hapax (ce terme ne se retrouvant nulle part ailleurs, ni dans le Bouclier, ni en un autre endroit de l'Iliade). Ce seraient déjà deux motifs suffisants pour qu'on attende de ce passage une mise en ouvre exceptionnelle. Mais ce n'est pas tout : que

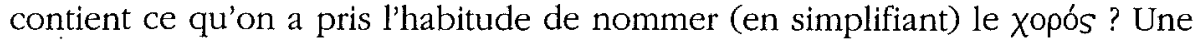
constellation de prouesses artistiques réunissant l'architecture, la danse, l'art des textiles poussé jusqu'à ses raffinements les plus extrêmes ${ }^{102}$, le travail des métaux également (avec couteaux et baudriers), ainsi que l'agilité des acrobates - sans compter les savoirs du potier et de l'aède (dont il s'impose à nos yeux de rétablir la mention aux vers $604-605)^{103}$. C'est trop pour qu'on puisse ravaler cette conjonction inégalée au rang d'une simple énumération destinée à camper un décor agréable. Certes non sans raison, cette scène a jusqu'ici attiré l'attention par son caractère festif extraordinaire : on y a vu avant tout un morceau de pure réjouissance, dans un moment privilégié de totale réconciliation, d'authentique «communitas » ${ }^{104}$, après les évocations mélangées contenues dans ces scènes qui, même censées décrire une ville en paix ou un monde campagnard, faisaient place aux dissensions d'un procès

102 Avec tissage et traitement à l'huile (de quelque manière qu'on doive l'entendre). Cf. Taplin, Sbield (supra, n. 1), p. 9. Depuis cet art., il a été abondamment montré que les arts du textile pouvaient constituer un archétype de l'art poétique : $c f$. entre autres SCully, 1990 (supra, n. 20), p. 173, n. 5; J. Scheid \& J. Svenbro, Le métier de Zeus, mythes du tissage dans le monde gréco-romain, Paris, 1994 (et cf. infra, n. 172).

103 Les vers 604-605 manquent dans les manuscrits, mais constituaient une variante d'Aristarque, connue d'Atthénée (181b). Sur cette question cf. TAplin, Sbield (supra, n. 1), p. 20, n. 27 et STANLeY (supra, n. 1), p. 303-304, n. 5. On a même pu, pour la représentation du poète, parler de l'« omphalos» du Bouclier (Hanna Philıp, Die Kosmographie Homers, in MDAI, 99 [1984], p. 1-4, spéc. p. 3; voir encore M. Fonderer, Der Sänger in der bomerischen Scbildbescbreibung, in Synusia. Festgabe für W. Scbadewaldt, Neske, 1965, p. $23-28$.

104 L'expression est de Redfield (supra, n. 1), p. 188. Becker, 1995 (supra, n. 3), p. 147, parle de « haut degré d'engagement dans les plaisirs de l'art ». 
ou à la dilacération sanglante des plus belles bêtes d'un troupeau; il n'y a pas à repousser cette interprétation. Mais il semble difficile de s'en contenter, et de ne voir que l'exaltation des joies relativement modestes de la vie pacifique, dans une pièce que tant de points désignent comme unique. Il serait en effet préjudiciable à la compréhension de ce passage de méconnaître la place prééminente qu'y occupe le domaine de l'art ${ }^{105}$ en se bornant à lui attribuer une simple valeur de lien social. Qui plus est, si les différentes composantes du texte et de la surface réfléchissante qu'est le Bouclier sont aussi soigneusement agencées que nous pouvons le présumer et que le poète le donne

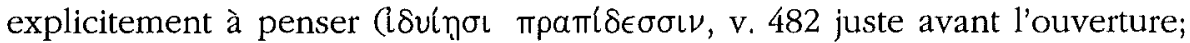

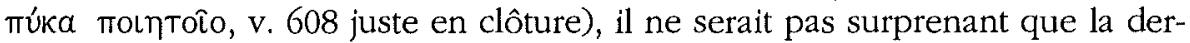
nière scène ouvrée par le dieu soit aussi intimement liée à l'ensemble que les autres éléments, et livre des indices décisifs pour l'interprétation globale de la pièce entière. L'intérêt même de ces vers, leur cohérence par rapport au reste de l'œuvre, apparaîtraient considérablement amoindris si l'on devait, après tout ce qui vient d'être avancé, renoncer à les situer dans la perspective du poème et de sa signification.

Commençons par considérer la scène de danse, dont l'évocation entraîne toutes les autres. Et rappelons d'emblée qu'ailleurs dans le poème, la danse est affectée de connotations péjoratives en ce qu'elle constitue, en repoussoir, un symbole de la carence des vertus guerrières ${ }^{106}$, un emblème du gaspillage futile d'énergie. Or il ne semble pas douteux qu'elle serve ici à signaler le comble de l'excellence artistique, en même temps qu'elle représente un symbole du monde et de la vie. Il s'en faut en effet de beaucoup qu'on ait affaire à une scène orchestique purement décorative ${ }^{107}$, et la multiplicité d'harmoniques qu'elle développe oblige à se poser quelques questions. Déjà

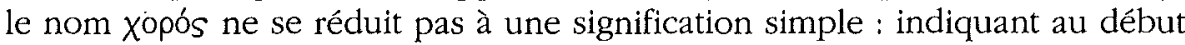
(v. 590) un lieu, la place où ( $(k \nu \theta a)$ se déroulent les évolutions des jeunes gens, il en vient ensuite $(v, 603)$ à désigner le groupe même des danseurs gracieux

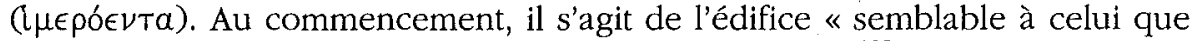
construisit avec soin Dédale à Cnossos pour Ariane... » ${ }^{108}$. Ce renvoi du dieu

105 Edwards fait justement observer (1990 [supra, n 1.], p. 278), que l'adjectif qui revient le plus souvent pour ces scènes est ka入ós : 491, 518, 524, 562, 588, 602 (en bonne place dans le vers).

106 Il. III, 54; XV, 508; XVI, 617, 745-50; XXIV, 261; cf. TAplin, Sbield (supra, n. 1), p. 6 \& n. 14.

107 La supposition même en est inconcevable, dans un contexte où la danse possédait une valeur religieuse si éminente : J.W. FitTon, Greek Dance, in CQ, 23 (1973), p. 254-274; Aubriot, 1992 (supra, n. 17), p. 176, n. 181; S. LonsDAle, 1993 (supra, n. 53), en partic. p. 111 sq.; A. Motrte, La fête philosophique et le loisir des dieux, in J.M. ANDré, J. Dangel, et P. Demont (éds), Les loisirs et l'béritage de la culture classique, Actes du XIIIè Congrès de l'Association Guillaume Budé, Bruxelles, 1996, p. 37-53. Cela confère un poids accru aux passages mentionnés dans la $\mathrm{n}$. précédente.

${ }^{108}$ Et qu'il ne faut probablement plus chercher dans le « théâtre » quadrangulaire découvert par Evans, mais dans un groupe de plate-formes circulaires surélevées : $c f$. 
à $\Delta a i \delta a \lambda o s$, l'architecte mythique si bien nommé ${ }^{109}$, souligne certainement des qualités artistiques hors de pair. Mais il fournit également un autre exemple de l'inversion des points de référence que nous avons vue pratiquée dans ce morceau du Bouclier : ici encore, comme pour les dieux comparés à " des mortels vivants " (v. 539), comme pour la jachère d'or « semblable à une terre labourée » (v. 548), il y a un effet pour ainsi dire de "contre-imitation », par lequel ce n'est pas le monde des héros qui s'inspire des dieux ${ }^{110}$, mais au contraire l'ouvrage divin qui s'ingénie à imiter le vivant et le périssable ${ }^{111}$. Cette référence à Dédale et à Cnossos produit encore un autre effet, qui est d'orienter ver's l'évocation de la yépavos, la danse aux figures circulaires alternées que, selon Plutarque, Thésée institua à Délos « en mémoire des détours du Labyrinthe ${ }^{112}$. La présence en ces vers des noms de Cnossos, de Dédale et d'Ariane (les seuls noms propres du Bouclier - hormis ceux des dieux aux

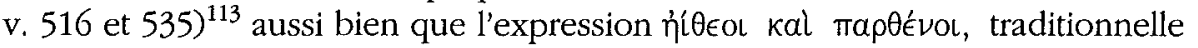
dans le contexte de cet épisode mythique de la victoire sur le Minotaure, incitent à penser ici à cette danse crétoise ${ }^{114}$. Au reste, un contexte rituel se

P. WARren, Circular Platforms at Minoan Cnossos, in ABSA, 79 (1984), p. 307-323, spéc. p. 323 , où le rapprochement avec notre texte est explicite. Que Dédale soit en relation avec la danse circulaire est attesté par l'Eutbypbron de Platon (15b). Sur la polysémie du nom xopós, cf. Cl. Calame, Les chcurs de jeunes filles dans la Grèce archaíque, Rome, 1977, I, p. 52; LoNsDale, 1993 (supra, n. 53), p. 115 sq.

109 Cette sorte d'ombre portée par Dédale sur Héphaïstos, de primauté de l'homme sur le dieu (pour ce qui est du point de comparaison), a beaucoup chagriné certains scholiastes (Nicanor in Venetus Græcus 822: H. ERbse, Scholia Graeca in Homeri Iliadem, 4, p. 564-6; cf. Sarah Morris, Doedalus, Princeton, 1992, p. 99, n. 76; $c f$. aussi K. SNIPEs, Literary Interpretation in the Homeric Scholia : the Similes of the Iliad, in AJPb, 109 [1988], p. 196-222). N'oublions pas pourtant que dès lẹ début le dieu « ouvrait » le bouclier de

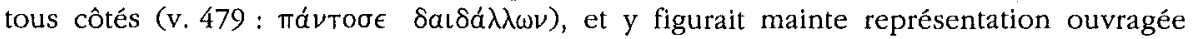
(v. 482 : $\delta \alpha(\delta \alpha \lambda \alpha$ по $\lambda \alpha \alpha$ ). Cf. Morris, p. 13 sq. : retenons son observation judicieuse (p. 1819) selon laquelle tous les $\delta a \iota \delta a ́ \lambda \epsilon a$ de l'Iliade sont en rapport étroit avec Achille.

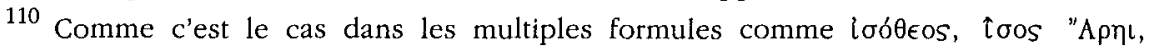

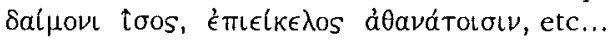

111 Cette imitation s'établit sur trois plans : celui de la mortalité des hommes (539), celui de la matière même de la terre qu'ils travaillent (548), celui de l'élaboration artistique à laquelle ils s'efforcent (591), i.e. que sont recouverts les trois domaines : de la nature ontologique de l'homme, de sa vie quotidienne, de sa culture; $c f$ supra, n. $62 \& 77$.

112 Plut., Thésée, 21.

113 L'absence de noms propres dans le Bouclier (en partic. de celui d'Achille) a été remarquée par J. Labarbe, Survie de l'oralité, in Cl. Baurain, C. Bonnet, v. Krings (éds), Phoinikeia Grammata. Lire et écrire en Méditerranée, Actes du Colloque de Liège de nov. 1989, éd. , Liège-Namur, 1991, p. 499-531, spéc. p. 504, n. 17.

114 Cf. J. Van Oóteghem, La danse minoënne dans l'fliade (XVIII, 590-606), in LEC (1950), p. 323-333. 'Hí日eo est le titre de l'Ode 17 de Bacchylide, qui est précisément con-

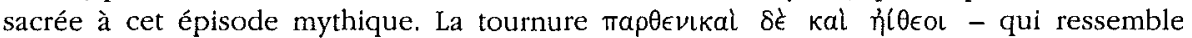

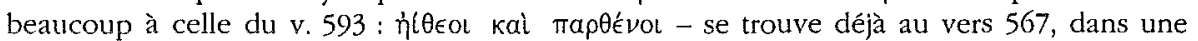
scène dont nous avons fait observer (supra, n. 53) qu'elle présente un chant aux con- 
laisse deviner à travers les noms oreфávas et $\mu a \chi a \operatorname{lpas}^{115}$, ce qui est approprié

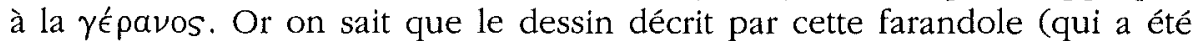
expliqué dès l'Antiquité ${ }^{116}$ comme une étiologie des figures du chour tragique), cherche dans le mouvement des astres le modèle de l'évolution des choreutes (mouvement diurne du ciel vers la droite et mouvement vers la gauche de la lune et du soleil) : ce tableau se raccorderait avec l'ouverture cosmique du Bouclier. Par ailleurs, même si la prudence s'impose pour décider de l'exacte valeur symbolique du labyrinthe, un symbolisme de mort et de renaissance semble bien affleurer dans la $\gamma^{\prime}$ éavos ${ }^{117}$. Or aux cercles de ces danseurs ${ }^{118}$ font écho un peu plus loin les tours des acrobates qui, eux non plus, ne sont probablement pas là comme en un spectacle de foire : leurs sauts en effet pourraient bien passer pour une évocation en transparence de la haute voltige qu'est « le grand saut", puisque, même si le symbolisme funéraire de l'acrobatie n'avait pas été démontré ${ }^{119}$, le mot $\kappa v \beta \iota \sigma \tau \eta T \eta ̂ \rho \epsilon$ (v. 605) serait là pour convoquer le souvenir de Kébrion ${ }^{120}$ trouvant la mort

notations ambiguës, le Linos, et dont (nous allons le voir) il s'impose de sentir les relations avec celle-ci (cf. infra, p. 42-43).

${ }^{115}$ V. 597. Én effet ce type de couteaux de sacrifice était déplacé à la danse, disait déjà Aristarque : $c f$. VANDERLINDEN (supra, n. 9), p. 116. Sur la $\mu a ́ x a \iota p a$, outil sacrificiel par excellence, $c f$. J.-L. Durand, Sacrificare, dividere, ripartire, in C. GRotTanelli, N.F. Parise (éds), Sacrificio e societa nel mondo antico, Rome-Bari, 1988, p. 193-202, spéc. p. 197-199. Une semblable discrétion concernant l'évocation des réalités cultuelles a déjà été relevée supra, n. $35 \& 64$.

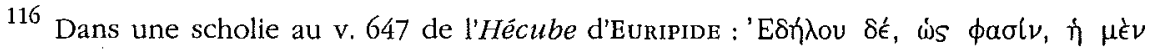

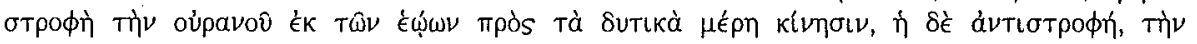

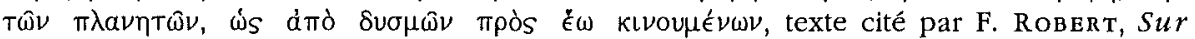
l'origine du mot tragédie, in Mélanges d'archéologie et d'bistoire offerts à Charles Picard, Paris, 1949, t. II, p. 872-880, p. 874). Certaines recherches plus récentes relatives au choeur lyrique orientent dans la même direction (J. Irigoin, Arcbitecture métrique et mouvements du chour dans la lyrique chorale grecque, in REG, 106 [1993/2], p. 283-302, spéc. p. 291), qu'accréditent plusieurs scholies à Pindare ( $c f$. A.B. DrachmanN, Scbolia vetera in Pindari Carmina, Leipzig, 1927, III, p. 306-307, 310-311).

117 Chacune des hypothèses énumérées par Frontrisi-Ducroux, Dédale (supra, n. 15), p. 148, apporte un trait pertinent dans notre perspective. Voir aussi Morris, p. 186-188.

118 Il a été proposé de manière convaincante de voir dans ces «tours » une anticipation de la course entre Hector et Achille en XXI : cf. R.J. RABEL, The Shield of Achilles and the Death of Hector, in Eranos, 87 (1989), p. 81-90.

119 W. Deonna, Le symbolisme de l'acrobatie antique, Bruxelles, 1953, p. 82 sq. Sur le rapport entre le kybistétère et l'eau (celle du plongeon, celle de l'Océan), ibid., p. $108 s q$.

${ }^{120}$ Il. XVI, 745; 749; $750:$ cf. Di BenedetTo (supra, n. 6), p. 7-10. La comparaison avec un " plongeur " est au v. 742. On songe évidemment à celui de la tombe de Pæstum : $c f$. M. Napoli, La tomba del tuffatore, Bari, 1970; P. Somville, La tombe du plongeur, in Études grecques, Liège-Bruxelles, 1990, 25-33. Au sujet du «plongeur » du chant XVI, on a pu parler de "the only truly extended metaphor in the Iliad" (C. Moulton, Homeric Metaphor, in $C P h, 74$ [1979], p. 279-293, spéc. p. 287). Cette fois, le rappel de cet épisode semble difficilement évitable, les v. 745-750 du chant XVI ne contenant pas moins de trois occurrences d'un mot de la famille de кußıттпті̄pes. On retiendra que les v. 775-776 de 
dans un «plongeon» qui le fait tournoyer à bas de son char. En conséquence, ces figures orchestiques et acrobatiques apparaîtraient en relation aussi étroite avec le reste du poème que pouvaient l'être les autres tableaux du Bouclier, puisque se laissent établir des rapports d'ordre poétique intérieurs au Bouclier lui-même (avec les mouvements célestes), et extérieurs (avec les «plongeons »). De plus ces rapports qui, concernant la relation de l'artiste au cosmos et à la mort, ne laissent pas de toucher au fond même de l'œuvre ${ }^{121}$, situent cette scène dans le sillage des précédentes.

Ensuite vient s'ajouter une comparaison avec un potier qui, essayant son tour, lui imprime des mouvements rotatifs. Pourrait-il s'agir d'un simple renseignement destiné à faire comprendre la perfection des cercles décrits par les danseurs ou, pire, d'une banale référence à la vie quotidienne, avec l'évocation du spectacle trivial d'un artisan au travail ${ }^{122}$ ? De fait cette comparaison mérite doublement de retenir l'attention, d'abord par son caractère unique, puisque c'est la seule de tout le Bouclier ${ }^{123}$, ensuite par sa texture exceptionnelle en ce qu'elle emprunte son «.comparant» au monde de l'art, et non à celui de la vie comme il est habituel dans l'Iliade ${ }^{124}$. Ce sont en effet deux activités artistiques (la danse et la poterie) qui sont ici reliées entre elles. Cela invite à retrouver dans cette ultime vignette un prolongement modifié de la variation appliquée au procédé poétique de la comparaison : alors que dans les vignettes champêtres il s'agissait ${ }^{125}$ d'un mouvement d'inversion de point de vue (la thématique restant la même), c'est ici un autre moyen qui est mis en œuvre, grâce au choix d'une thématique différente : l'imitation par le

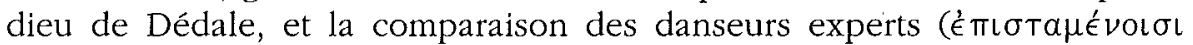
$\pi o ́ \delta \epsilon \sigma \sigma l$, v. 599) à un potier, constituent une cascade d'assimilations bien de

ce chant offrent de plus un indice d'une possible assimilation de Kébrion à Achille : $c f$. M. Willcock, Neoanalysis, in New Companion, (supra, n. 94), p. 174-189, spéc. p. 177.

121 La menace toujours suspendue de la mort est encore ici présente, au plein cour

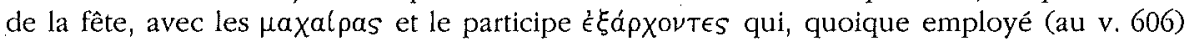
dans un contexte apparemment joyeux, est un terme technique du vocabulaire de la lamentation (Alexiou [supra, n. 53], p. 131 sq.).

122 Cette remarque ne vise pas à nier que les comparaisons introduisent une distance par rapport au monde héroïque, et rapprochent de la vie quotidienne (cf. S.L. ScHEin, The Iliad: Structure and Interpretation, in New Companion [supra, n. 94], p. 345-359, spéc. p. 358). Mais elle s'inscrit en faux contre l'idée que la banalité est projetée au premier plan pour aider à la compréhension de réalités autrement absconses.

${ }^{123}$ Cf. TAplin, Sbield (supra, n. 1), p. 9. Ce recours unique (en tous les sens du terme) à la comparaison des évolutions des danseurs avec le travail du potier, n'invite-t-il pas à s'interroger sur de possibles correspondances entre la création artistique en général et le monde, quand bien même la métaphore du potier n'aurait pas pu passer chez Platon pour l'une des figurations du démiurge (Tim. 33b, et même 73e; cf. L. BRIsson, Le même et l'autre dans la structure ontologique du Timée de Platon, Sankt Augustin, Academia Verlag, $1995^{2}$, p. 44-46).

124 Cf. Eliza G. Wilkins, A Classification of the Similes of Homer, in Class. Weekly, 13 (1920), p. 147-150, et les études citées supra, n. 40.

125 Cf. supra, p. 27-28. 
nature à confirmer que tout dans ces vers converge vers l'art (peut-être même vers l'art en tant qu'il mime une réduplication du monde). Toutefois il faut remarquer que cette comparaison du potier ne vaut que pour une partie des évolutions des danseurs: ceux-ci parfois décrivent aussi des «lignes» ( $\sigma$ Tíxas, v. 602), terme si volontiers présent dans l'lliade pour désigner les rangées de soldats ${ }^{126}$. Cela ne nous ramène-t-il pas à la réalisation accomplie par le poète (dont une image est mentionnée tout de suite après), plutôt qu'à

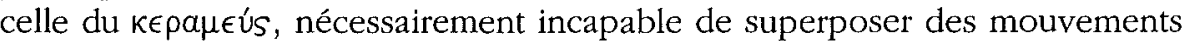
linéaires à des mouvements circulaires? L'autre $\theta \in$ Ios ảotós qu'est Homère peut, lui, réussir le tour de force (que réalise également le dieu ${ }^{127}$ ) de représenter des affrontements sans pour autant renoncer à figurer les révolutions alternées dans lesquelles se résolvent les antinomies - et ainsi faire de son œuvre un reflet des tribulations humaines en même temps que de l'harmonie du cosmos. C'est pourquoi, si nous avons pu dégager une structure en deux parties sensiblement égales et complémentaires d'involutions inversées, aux deux masses équilibrées en chiasme ${ }^{128}$ avec deux chutes en écho antinomique, nous devons être également sensibles au double mouvement ascendant parallèle qui scande le rythme de ce Bouclier, avec une première volée de vers allant jusqu'au Linos (v. 490-572), une seconde jusqu'au Xopós (v. 573606). Plusieurs similitudes en particulier laissent apercevoir que ces deux tableaux sont faits pour se répondre. Ainsi de la mention des jeunes gens et des

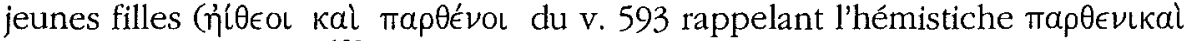

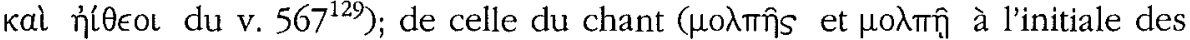

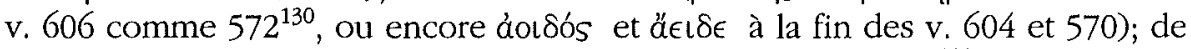

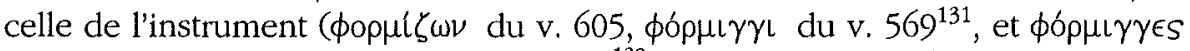
du v. 495); de celle du plaisir ou du désir ${ }^{132}$ (i $\mu \in \rho o ́ \in \nu T \alpha$ du v. 603 et i v. 570) - à quoi il faudrait ajouter le public qui fait cercle (év $\mu \epsilon ́ \sigma \sigma o l \sigma L, 507$,

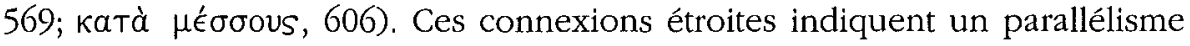

126 Cf. supra, n. $46 \& 74$.

127 Puisque le Bouclier (comme l'Iliade dont il est le reflet) parvient à superposer une progression linéaire à une structure annulaire.

128 Cf. supra, p. 32.

${ }^{129}$ Cf. supra, n. 114. Peut-être y a-t-il également écho avec une formule identique (mais au singulier), répétée avec insistance par Hector au chant XXII, 126-130; $c f$. TAPLIN, Homeric Soundings (supra, n. 19), p. 235; pour le rapprochement avec VI, 516, où figure

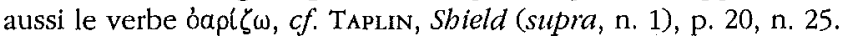

${ }^{130}$ Ce nom ne se trouve par ailleurs dans l'Iliade qu'en I, 472 pour un péan (comme moyen de propitiation d'Apollon par les Achéens) et en XIII, 637, dans un contexte orchestique comme ici (pour opposer chant et danse à la bataille).

131 La même fin de vers se retrouve en IX, 186 pour Achille (cf. 194). À part lui, le seul autre à toucher de la cithare dans le poème est Apollon (I, 603; XXIV, 63).

${ }^{132}$ Mot dont - à une exception près où il s'agit du désir de nourriture (XI, 89) - on remarque l'application, dans le reste du poème, au désir amoureux (III, 139; 446; XIV, 170; 198; 328); ou au « désir » des sanglots et des pleurs (XXIII, 14; 108; 153; XXIV, 507; 514): autre exemple d'amphibologie du vocabulaire homérique. 
entre ces deux morceaux consacrés au chant et à la danse. Le premier (le $\Lambda(\nu 0 s)$ est une brève scène musicale terminant une mise en abyme spéculaire de l'Iliade (dans sa double expression poétique du récit et du contre-récit) qui ne remplit pas moins de quatre-vingts vers (490-572); tandis que le second (le Xopós) occupe presque autant de vers que les deux vignettes pastorales (véritable métamorphose au-delà du miroir) auxquelles il fait suite. L'accroissement de l'importance relative de la danse et du chant dans chacune des deux séquences marque le changement de point de vue, quand on passe de l'art de «l'enfant » à celui de "l'aède divin » ${ }^{133}$. En tout cas, ce nouveau découpage (qui ne s'arrête plus au v. 589, mais mène jusqu'au v. 606) vient ajouter deux lignes ascendantes successives à la construction en chiasme, tournoyante, que nous décelions jusqu'au vouós. Cette superposition de deux constructions, annulaire et linéaire, fait retrouver les deux sortes d'évolutions des danseurs du Bouclier, mais aussi les deux types de chœur (processionnel et circulaire) ${ }^{134}$. Cette conjonction des mouvements circulaires et rectilignes trouve surtout un exact parallèle dans la structure du poème ${ }^{135}$, dont il a été montré que deux principes complémentaires gouvernent l'organisation; l'un, de symétrie pour ainsi dire statique, est fondé sur les balancements et la composition annulaire; l'autre, dynamique et linéaire, déploie une progression dramatique entre le début et la fin du poème $\mathrm{e}^{136}$.

Par ailleurs, si l'on en revient à la yépavos, les implications cosmiques de la scène de danse (aux parcours circulaires alternés reproduisant les mouvements inversés du ciel diurne et du ciel nocturne) s'adapteraient, elles aussi, au moins autant au poème qu'au vase artistement tourné. En effet considérer dans son rapport au texte poétique cet élargissement des évolutions des danseurs au monde tout entier, semble s'imposer d'autant plus que justement la description du bouclier divin (qui va, quelques vers plus loin, se clore sur la limite d'Océan) s'ouvrait sur la présentation (v. 484-5) des deux mouvements

133 Certaines reprises flagrantes à l'intérieur même du Bouclier viennent soutenir l'idée de ce parallèle (en gradation) entre deux transpositions, de plus en plus abstraites, de la matière de l'Iliade: si les v. 520-534 comportent plus d'un point commun avec la vignette des bovins, ils se terminent aussi avec un d $\lambda \lambda \hat{n} \lambda$ ous à la coupe du v. 534 rappelé

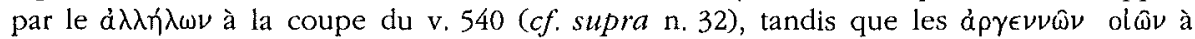
l'initiale du v. 529 se retrouvent en chiasme à la fin du v. 587 - tous rapprochements qui viennent corroborer notre proposition de voir dans les séquences animales une imagerie " distanciée » des séquences belliqueuses.

${ }^{134}$ Sur les deux catégories essentielles de l'iconographie du chour lyrique, « l'une de type processionnel, l'autre de type circulaire », cf. Calame, Cboeurs (supra, n. 108), I, p. 8384.

135 Telle que la dégage Schein, The Mortal Hero (supra, n. 16), p. 30-36. De son côté, Di BenedetTo (supra, n. 6), p. $87 \mathrm{sq}$. souligne la correspondance entre les structures parallèles des v. 595-596 et 597-598, et le mouvement rythmiquement équilibré de la danse.

136 Aussi bien les bijoux ouvrés par Héphaisstos pour Thétis et Eurynomé respectaientils cette complémentarité entre le droit et le courbe (Il. XVIII, 401). 
opposés décrits au ciel, par « le Soleil infatigable et la Lune en son plein » dans un sens, et dans l'autre par toutes les étoiles ${ }^{137}$. L'œuvre du dieu telle que la présente le poète se trouvait donc ainsi placée d'emblée sous le signe cosmique. On sait le parti qui dès l'Antiquité avait été tiré de la mention de ces phénomènes, pour interpréter le Bouclier comme «Imago Mundi » ${ }^{138}$. Une fois de plus ${ }^{139}$, il ne s'agit pas de récuser cette interprétation. Mais peutêtre cette fois encore doit-on aller plus loin en faisant ressortir le lien qui unit cette « image du monde " au reflet de l'lliade qu'est selon nous le Bouclier. En effet, tant qu'on croyait n'avoir affaire qu'à la « description » d'une ouvre plastique, on ne se montrait peut-être pas assez attentif au caractère cosmogonique, d'ordre proprement poétique, qui affecte cette ouverture.

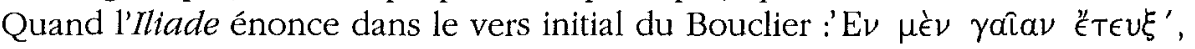

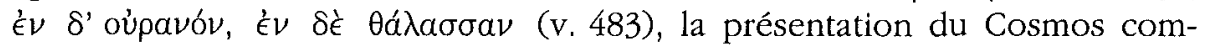
mence bel et bien à la manière de la cosmogonie hésiodique; car avec la terre, le ciel et la mer, on retrouve (à l'ordre près) « le ciel, la terre ferme et l'étendue marine » qui chez le poète béotien arrivent à l'existence quand la substance indifférenciée qu'est Gaia donne naissance à Ouranos, aux Montagnes et à Pontos (Théog, 126-32) ${ }^{140}$. Mais cette similitude formelle est d'autant plus frappante qu'elle va de pair avec une perspective tout opposée ${ }^{141}$ : on ne penserait pas, pour notre texte, à parler de « genèse » du monde, puisqu'il n'y a pas (comme dans la Théogonie) de naissance, ni même de venue à l'existence de réalités physiques élémentaires. Tout ici est artefact : il n'est ques-

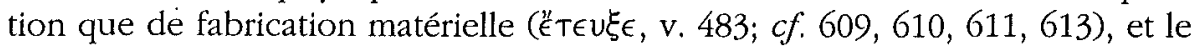

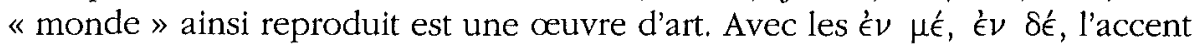

137 Que ces étoiles soient considérées dans leur mouvement circulaire est confirmé

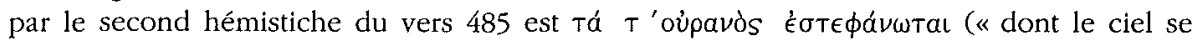
couronne »). Sans doute est-il plein de sens que ce verbe - ainsi que les noms (cités juste

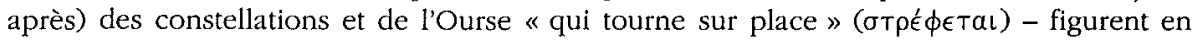
bonne place dès l'introït du Bouclier. Toutefois, plutôt que de mettre l'accent, à la suite d'EDwards, 1990 (supra, n. 1), p. 280-81, sur l'importance du lever et du coucher des Pléiades et des Hyades pour les saisons et les travaux agricoles, et de l'Ourse pour guider les navires, autrement dit plutôt que de rapporter la mention de ces corps célestes à leur seule utilité pour le fermier ou le marin, il semble préférable de considérer aussi leur rapport au reste de l'œuvre, voire leur possible signification symbolique ( $c f$. infra, n. 170 \& 171). On trouvera un développement important sur le Bouclier d'Achille et ses implications (entre autres) astronomiques dans Françoise Bader (supra, n. 76), III, 10 sq.

138 HARdie (supra, n. 1).

139 Cf. supra, n. 3 \& p. 22.

140 Cf. J. RudHARDT, Sur la possibilité de comprendre une religion antique, in Numen, 11 (1964), p. 189-211, spéc. p. 196, repris dans Du mythe, de la religion grecque et de la comprébension d'autrui, Cabiers Vilfredo Pareto, Revue européenne des Sciences sociales, 19 (1981), p. 13-32.

141 Nous avons déjà formulé un autre point de divergence en même temps que de contact entre Homère et Hésiode à propos des Îles des Bienheureux (supra, n. 91 \& 94). Ajoutons que le texte homérique ne poursuit pas sur des généalogies divines, mais sur un monde humain. 
est mis sur les adjonctions successives qui donnent forme à la création artistique ici évoquée, qu'il s'agisse de celle du dieu orfèvre ou de celle du poète. N'est-ce pas ce que suggèrent les deux derniers vers (607-8, avec le retour d'Océan en rondeau), où l'on ne sait si l'extrême rebord du bouclier solidement agencé ${ }^{142}$, bien construit, à la création bien méditée, vient clore l'œuvre de l'un ou celle de l'autre? En conséquence, si cette ouverture du Bouclier appelle discrètement le parallèle avec une cosmogonie, c'est pour

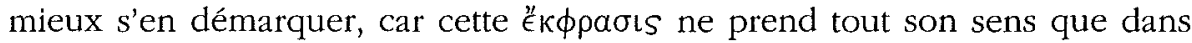
l'œuvre qui l'englobe.

Aussi bien la mise en place du Soleil et de la Lune nous ramène-t-elle tout de suite au poème, en contrastant avec un passage où la confusion du combat était exprimée par la désorganisation du monde : on ne savait plus dire « si le Soleil et la Lune existent encore»(XVII, 367). Au rebours, sur l'œuvre divine ${ }^{143}$, le monde est en ordre, mais d'un ordre fondé sur l'harmonieuse opposition des contraires, et tout l'univers apparaît solidaire ${ }^{144}$, comme le marque l'achèvement par la clôture océane, elle-même circulaire et au cours rétrograde ${ }^{145}$. Or Océan (qui fut le lieu, sous la protection de Thétis $^{146}$, de l'initiation artistique d'Héphaïstos ${ }^{147}$ ), indique la frontière du monde des morts ${ }^{148}$ tout comme il est « à l'extrême bord » du b/Bouclier núka

142 Cf. supra, p. 40.

143 Cela s'inscrit admirablement bien dans le parti-pris d'inversion qui nous semble décelable à chaque vers du Bouclier : l'inversion dans les procédés poétiques reflète une inversion de perspective sur la vie et la mort, sur les hommes et les dieux, en même temps que l'alternance des révolutions des corps célestes, des danseurs, du tour du potier, du cours d'Océanos - le tout étant bien suggéré par tous les termes indiquant le

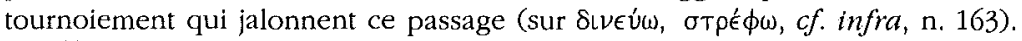

${ }^{144}$ En vertu d'une conception qui devait parcourir toute la pensée archaïque : $c f$. Aubriot, 1992 (supra, n. 17), p. 291; 372-373. Mais cette solidarité des éléments entre eux exclut toute confusion (cf. infra, n. 148).

145 Il. XVIII, 399 : ał d'Océan doive quelque chose au Dracon Ouroboros qu'on trouve sur la bordure de certains bols phéniciens ou chypriotes des environs du vil ${ }^{\mathrm{e}}$ s. (cf. C. Hopkins, Astrological Interpretations of Some Pbonician Bowls, in Journ. of Near Eastern Stud., 24 [1965], p. 2836, spéc. p. 31). Cela n'empêche pas de lui accorder aussi une signification interne au poème.

146 De Thétis et d'Eurynomè : XVIII, 402-3. Héphaïstos était donc lui aussi entouré par l'Océan.

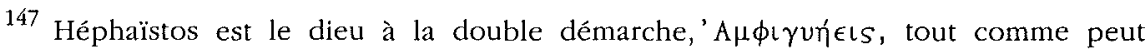
s'inverser le cours d'Océan. L'inversion du cours d'un fleuve est l'doúvatov par excellence. Mais le cours d'Océan est circulaire : $c f$. J.S. Romm, The Edges of Earth in

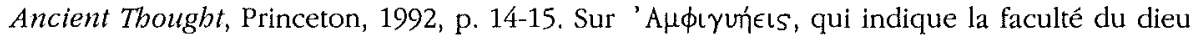
(particulièrement appropriée ici) de se déplacer "dans les deux sens à la fois », $c f$. M. Detienne, J.-P. Vernant, chap. "Les pieds d'Héphaïstos », in Les ruses de l'intelligence. La mètis des Grecs, Paris, 1974, p. 256.

148 Od. XI, 158. Sur Océan, implantation de l'île des Bienheureux, frontière du monde des morts, $c f . \mathrm{J}$. RudhARDT, Le thème de l'eau primordiale dans la mythologie grecque, 


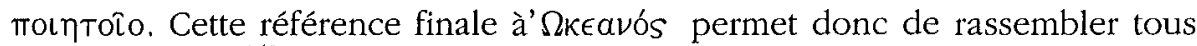
les fils du texte ${ }^{149}$. Elle est conforme aux habitudes poétiques de composition annulaire, mais avec une propriété particulière à la forme du bouclier ${ }^{150}$ et à sa signification. Elle est également adaptée au dieu maître d'œuvre tout comme au destinataire puisque, le destin n'eût-il été déjoué par le mariage avec Pélée, Thétis devait mettre au jour « le maître du monde ${ }^{151}$ - tandis que le Péléide est seulement un homme qui, d'ascendance immortelle, vient d'accepter sa mortalité. Aussi cette œuvre divine - qui embrasse d'un même regard et à même distance la vie et la mort, pour les intégrer aux révolutions cosmiques - est-elle effroyable à voir pour quiconque n'est pas Achille ${ }^{152}$. Ce bouclier, qui se distingue des autres en ce qu'il ne représente presque rien d'explicitement épouvantable, de fait épouvante. Car il renvoie le commun des mortels à un autre plan de l'être, qui leur est inaccessible, où vie et mort sont indifférentes. Sa constitution même charge de sens la mort future d'Achille puisque, des cinq couches qui s'y superposent, celle d'or, au milieu, devait arrêter les traits comme c'est le cas effectivement à deux reprises ${ }^{153}$. Mais le fait que cette protection soit seulement provisoire, que l'or divin luimême en fin de compte doive se révéler insuffisant pour préserver la vie

Berne, 1971, p. 87 sq.; et, selon Proclus, « principe de distinction entre divers ordres de réalité » (ibid., p. 91).

149 Cf. Pigeaud, 1988 (supra, n. 1), p. 60.

150 Puisqu'on peut le supposer rond : EDWARDs, 1990 (supra, n. 1), p. 278.

151 Cf. aussi Schein, The Mortal Hero (supra, n. 16), p. 92 . Sur la décoration cosmique du bouclier comme emblème royal, $c f$. les pages remarquables de Hardie (supra, n. 1), p. $22 s q$.

152 Personne d'autre que lui ne peut en soutenir la vue : XIX, 14-5. Les seules autres mentions qui soient faites de ce bouclier figurent en XXI, 241 \& XXII, 313, pendant les combats contre le Scamandre et contre Hector.

153 Il. XX, 268-272. A bien considérer le texte, cette protection offerte par " l'or, présent du dieu ", est présentée comme assurant la confusion d'Enée plutôt que la sécurité d'Achille. Ces quatre vers sont les seuls à jeter quelque lumière sur la composition métallique du bouclier d'Achille, énigmatique au point d'avoir découragé Aristarque ( $c f$. la n. ad loc. de Paul Mazon dans son édition de la CUF). Selon ce passage, d'or est composée la couche médiane, qui est recouverte à l'extérieur par deux couches de bronze, à l'intérieur par deux couches d'étain. Les couches faites de bronze peuvent être transpercées; notons que le bronze est le métal ordinaire dont sont constituées les armes des héros- quoique les boucliers soient plutôt tendus de peaux: l'ensemble donne beaucoup de peine à EDwArds, 1990 (supra, n. 1), p. 279-80. En revanche les couches faites d'étain, outre qu'elles sont sur ce bouclier inaccessibles (puisque protégées par l'or), semblent bien être infrangibles elles aussi; en effet, en XXI, 592-594, la jambière d'étain, elle aussi «présent du dieu », arrête la pique d'Agénor. Plutôt que de raisonner sur le poids excessif d'un bouclier aussi épais, sur l'ineptie qu'il y aurait à placer l'or en position invisible (EDWARDS, 1991 [supra, n. 28], p. 202), ne vaudrait-il pas mieux se tourner, là encore, vers une interprétation symbolique des métaux en question (par ex. le bronze aurait un rapport assez transparent aux guerriers, l'or pourrait symboliser la divinité ou l'immortalité, tandis que l'étain, plus difficile à interpréter, pourrait s'accommoder d'un rapport au monde infernal)? 
d'Achille, est une affirmation définitive de ce que la nature mortelle du héros est inéluctable.

Cependant, si ce bouclier (qui inaugure la tradition littéraire ${ }^{154}$ des écus miroirs de ceux qui les arborent et s'en protègent), est ici un « symbole » de son possesseur, il est, croyons-nous, plus encore un « symbole » du poème : les révolutions alternées décrites par le mouvement astral et par le mouvement sidéral (v. 484-485) nous font d'emblée trouver au ciel la réversibilité, cette même réversibilité qui affecte les procédés de composition des œuvres de l'orfèvre comme de l'aède, et qui trouve son expression poétique dans la projection, sur le Bouclier, du récit et du contre-récit de l'Iliade. Cette épopée en effet s'inscrit sans doute dans une tradition : celle où est exaltée la geste des héros ${ }^{155}$. Mais, s'attachant régulièrement (grâce aux comparaisons) aux réalités de la vie quotidienne, elle la dépasse et en montre les bornes ${ }^{156}$. Comme l'indique son titre, l'Iliade n'est pas un monument à la gloire d'un homme : c'est une œuvre qui concerne une communauté humaine avec toutes ses attaches - en face de laquelle se dresse une armée d'assaillants dominée par la haute stature d'un héros quasiment divin, aux liens familiaux peut-être distendus, mais mortel. De multiples indices montrent que ce poème accuse une distance prise par rapport au thème traditionnel de « l'immortalité » par le trépas glorieux, pour marquer un intérêt plus grand porté à la nature pour ainsi dire « ontologique » de l'homme ${ }^{157}$, dans sa grandeur mais aussi dans les limites de sa finitude ${ }^{158}$. Ces armes, forgées par un dieu à la demande d'une déesse, et remises à elle puis par elle, sont faites expressément pour mener son fils mortel vers son trépas : ce chef-d'œuvre est immortel, aussi sûrement qu'Achille va mourir, comme le déclare d'emblée Héphaïstos à Thétis ${ }^{159}$, soulignant ainsi de manière péremptoire

\footnotetext{
154 Cf. supra, n. 12.

155 Le poème accepte implicitement cette référence quand il montre, au chant IX, les

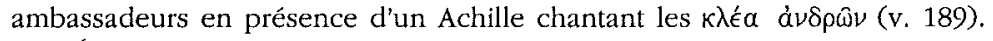

${ }^{156}$ Cf. supra, p. 37.

157 Semblable intérêt porté à l'homme dans l'Iliade ressort de certaines constatations
} de vocabulaire aussi bien que d'études qui concernent un personnage : $c f$. Auproto $L e$ divin Acbille et l'exaltation de l'bumain dans l'lliade (cf. supra, n. 5); Remarques sur l'usage de $\theta a ́ \mu \beta o s$ et des mots apparentés dans l'lliade, in Orpbeus, 2 (1989), p. 249-260; Humanité et divinité dans l'lliade (supra, n. 5).

158 Sans doute doit-on, à cet égard, méditer sur la tradition selon laquelle Achille aurait eu le choix entre deux vies: longue et obscure, ou brève mais glorieuse, qu'il choisit conformément à l'idéal ancien (on y trouve une allusion en I, 352-353 et en IX, 410 sq.). Mais la mort de Patrocle détermine chez le héros une palinodie : cette gloire, quand elle est à sa portée, a perdu pour lui toute saveur; on en trouve un écho dans sa déclaration désenchantée et amère d'Od. XI, $488 \mathrm{sq}$. (où il est au rang des autres trépassés). De cette ombre de gloire il goûte toute l'inanité.

159 XVIII, 463-467; cf. TAPLIN, Homeric Soundings (supra, n. 19), p. 204. Ce sont même ses seules paroles, à l'exception des mots de bienvenue (424-427). Cette signification emblématique du bouclier nous semble expliquer l'indifférence du passage aux autres 
l'inefficacité pratique de cette arme défensive par excellence, toute divine qu'elle est.

Pourtant, dans le grand naufrage qu'est toute vie humaine (comme Achille l'expose à la fin devant Priam ${ }^{160}$ ), le chant semble bien le seul réconfort qui vaille : même si l'œuvre d'art est impuissante à sauver de la mort, elle est pour les hommes une consolation aux douleurs de la vie ${ }^{161}$, par sa beauté sans doute, et peut-être aussi parce qu'elle les intègre à une perspective

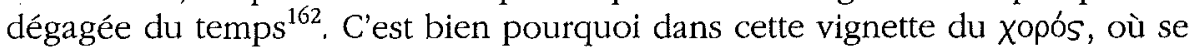
pressent des notations apparemment descriptives mais impossibles à se représenter, se trouve abolie toute fiction qui pourrait servir de vecteur temporel. Cette dernière scène ne renferme aucune péripétie, aucune action affectée d'un début ou d'un terme; tout y semble emporté dans un tourbillon

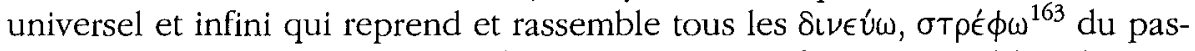
sage, comme s'employant à redessiner toutes les figures possibles d'opposition, d'alternance et de réversibilité. Si dans le vouós l'espace se réduisait aux seules indications de la verticalité et de l'horizontalité, si nous parlions, au sujet de la cinquantaine de vers placés sous le premier noínoe d'enjambe-

armes forgées par le dieu (simple énumération aux v. 609-613). Cf. supra, p. 13 \& n. 14. On peut trouver là un autre indice (avec la comparaison d'Héphaïstos à Dédale) du renversement (à l'occasion du Bouclier) des rapports homme/dieu - renversement provisoire, pour mieux assurer la mise en place de l'ordre auquel président les dieux; car si Homère avait vraiment jeté quelque doute sur la hiérarchie des mortels et des dieux, Hérodote aurait-il jamais fait de lui (conjointement avec Hésiode : II, 53) le fondateur, en quelque sorte, de la religion grecque?

160 Il. XXIV, $522 \mathrm{sq}$.

161 Tout comme elle constitue une jouissance pour les dieux : en un échange significatif, les dieux compatissants ont enseigné aux hommes la participation à de belles exécutions artistiques pour adoucir leurs peines (PLATON, Lois II, 653-654), et les mortels viennent leur en faire hommage comme d'une offrande capable de les apaiser; $c f$. Aubriot, 1992 (supra, n. 17), p. 458-460.

162 On observe une attention parallèle à éviter tous les contours trop précis, de personnages comme de paysages : Aubriot, Paysage (supra, n. 27).

163 Pour les mots de la famille de $\delta \iota v \in u ́ \omega, 494,543,606$; pour ceux de la famille de $\sigma \tau \rho \epsilon \phi \omega, 544,546$. Sans pouvoir les approfondir, relevons les échos qui sont ainsi déterminés entre le Bouclier et le reste du poème: d'abord avec les tourbillons du

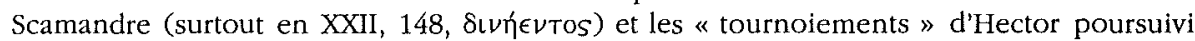

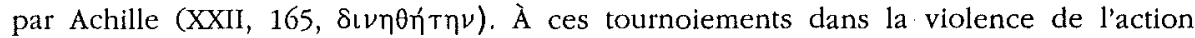
s'opposent les manifestations de la douleur solitaire d'Achille en deuil, quand il se tourne et retourne dans son lit ( $\epsilon \sigma \tau \rho \epsilon \phi \epsilon T(o))$, et qu'il va « tournoyer », éperdu, sur la

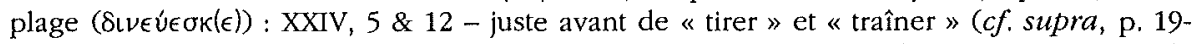
20) le corps d'Hector autour du tombeau de Patrocle, décrivant là une autre sorte de danse circulaire (XXIV, 15, 16, 20, 755); elle-même est reliée au carrousel équestre dont les Myrmidons honorent Patrocle (XXIII, 13-26) par des correspondances formelles étroites, puisqu'on y retrouve des termes proches de ceux qui sont rassemblés en XXIV, 15-18:

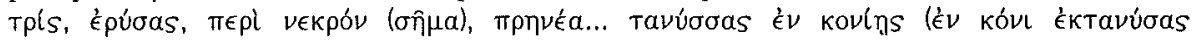
тротрпиє́a). 
ment de la succession chronologique du récit ${ }^{164}$, nous pourrions ici parler de confusion des temps - ou de leur anéantissement, ce qui revient au même ${ }^{165}$. Cette abolition de toute durée linéaire va de pair avec une sorte d'éclatement de l'espace qui, allant jusqu'à confondre lieux et personnes, se déploie dans toutes ses dimensions, le mouvement constituant (comme pour les révolutions célestes) la seule empreinte du temps ${ }^{166}$. Aussi les similitudes que nous

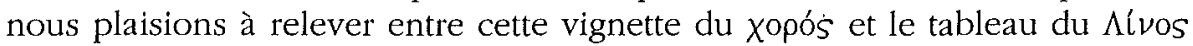
semblent-elles de nature à faire percevoir le passage à un registre supérieur bien plutôt qu'un parallèle au même niveau : le chant «léger » du $\pi \alpha$ ĩs du

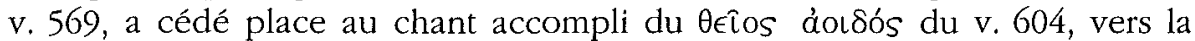
musique de qui tout converge ${ }^{167}$, bien entouré qu'il est par le chœur ainsi que par les acrobates et leurs culbutes : ce sont les plongeurs qui «préludent » ( $\epsilon \xi \dot{\alpha} \rho \chi 0 \nu T \epsilon S$ au v. 606) au chant - et non le chanteur qui prélude à la lamentation $^{168}$, et l'aède en question a une bien autre mission que celle des

164 Supra, p. 21.

165 Contribuent puissamment à cet effet la forme itérative $\theta \rho \epsilon ́ \xi a \sigma \kappa o$ " répétée aux v. $599 \& 602$, ainsi que les balancements et alternances fondés sur des procédés de style ou de vocabulaire divers : aux v. 594 et 602, les pronoms $\alpha \lambda \lambda \hat{n} \lambda \omega \nu$ et $\alpha \lambda \lambda \eta \dot{n} \lambda$ otol englobent d'abord deux distiques bâtis exactement sur le même modèle (fondé sur une opposition :

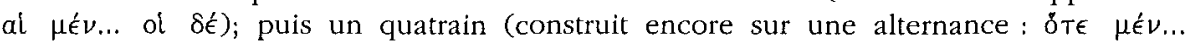

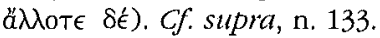

${ }^{166}$ Ce mouvement conjugue circularité et linéarité - tout comme la composition du passage (cf. supra, p. 44 \& n. 134) : ce qui, avec le Xopós, est censément représenté sur une partie de la surface du bouclier, ce sont d'abord des évolutions où l'harmonie de la fête fait une place aux rangées alignées et affrontẹes, la complémentarité réciproque trouvant à s'exprimer dans les rondes ou dans l'affrontement; puis, autour de l'aède et de sa musique, des cercles et des tournoiements dans l'alternance et dans la réciprocité. Les multiples ambiguités de vocabulaire qui attestent la complémentarité entre union englobante et séparation affrontée, entre procréation et mort, sont utilement rassemblées dans Schein, The Mortal Hero (supra, n. 16), p. 77 \& 189-190.

167 Cf. supra, n, 103. Au reste il a été montré que le sommet d'une ekpbrasis (cf. supra, n. 39) était à chercher dans sa dernière partie: J.Th. Kakridis, Erdicbtete Ekphrasen, Ein Beitrag zur bomeriscben Scbildbeschreibung, in WS, 76 (1963), 7-26, repris dans Homer Revisited, Lund, 1971, p. 108 sq. Le caractère essentiel de l'art sur le Bouclier (qui répond à la mise en relief du Bouclier dans le chant) est bien noté pat Stanley (supra, n. 1), p. 378 , n. 10. En manière de confirmation du découpage ici proposé, selon lequel les deux transpositions de l'Iliade qui se succèdent dans le Bouclier expirent sur une allégorie des déplorations funéraires artistiquement conduites - puisque la première « réfraction » (v. 490-572) du poème s'achève avec le Linos et la seconde (v. 573-606) avec le Xopós -, il faudrait ajouter que l'Iliade elle-même se termine sur une cérémonie de funérailles, celles d'Hector; et que dans cette scène précisément on retrouve, en plus d'autres termes communs avec nos deux tableaux - surtout kámeTos en XXIV, 797 (cf. supra, p. 26) -, la seule autre mention d'aèdes dans le poème (XXIV, 720).

168 Rappelons que l'une des raisons qui ont servi à justifier l'expulsion de cet aède est le caractère inhabituel d'ȩ́á $\rho \chi 0 \nu \tau \epsilon S$ « qui remplissent leur rôle... par rapport à un soliste et non par rapport à un groupe » (F. RoBenT, Sur l'origine de la tragédie et la signification du tragique, in LEC 32 [1964], p. 98-129, spéc. p. 124, n. 79). Mais justement

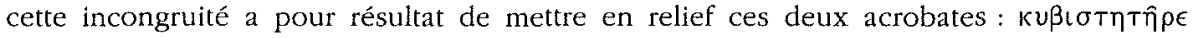


musiciens ordinaires dont la voix est faible : il est l'accomplissement des chanteurs traditionnels qui ne sont auprès de lui que des novices. Si la vignette de la vendange nous montrait un enfant comme chanteur d'un thrène (dont le nom, $\Lambda$ lvos, semble suggérer un début et une fin) pour pleurer un trépas, si la vignette du vouós peut faire penser à un contexte d'héroïsation (mais pour en repousser l'éventualité), la scène finale nous met en présence d'un artiste divin, autre Arctouros au pinacle du chef-d'œuvre de métal ${ }^{169}$, autre démiurge, qui - par-delà « la mort qui tout achève », mais aussi par-delà les espoirs d'immortalisation - chante la vie comme la mort et ainsi intègre son ouvre à l'harmonie binaire ou cyclique du monde et à ses révolutions alternées, au moyen d'un poème lui-même rectiligne et annulaire à la fois. Cependant, tout comme son appartenance à la constellation de l'Ourse prive Arctouros d'une participation au pouvoir régénérateur des eaux d'Océan $(v, 489)^{170}$, de même le poète, en dépit de son art, ne saurait faire qu'Achille soit immortel. Aussi le ciel forgé par Héphaïstos indiquait-il l'entrée aux frimas hivernaux ${ }^{171}$.

(v. 605), qui à la différence de Kébrion ne sont pas nommés (cf. supra, n. 120); une fois de plus, le résultat obtenu est l'abstraction (pour ainsi dire le plongeon sans le plongeur, comme les «sourires sans chats » de Lewis Carroll), tandis que le passage au duel pourrait indiquer une sorte d'égalité impartiale entre les camps (cf. supra, n. 32).

169 Entendons ici pinacle au sens figuré : nous ne voulons aucunement suggérer la moindre possibilité de proposer une restitution plastique de ce Bouclier, dont nous croyons qu'il est tout entier une transposition de l'Iliade, en même temps qu'il nous invite à une méditation sur le sens de l'œuvre poétique. Dans le contexte de la $\gamma$ '́pavos, il est intéressant de noter que la Grande Ourse, autour de laquelle tournent les autres corps célestes, était aussi nommée elle-même 'E $\mathrm{\lambda} \iota \mathrm{kn}$ (A. LE BçUFrLe, Les noms latins d'astres et de constellations, Paris, 1977, p. 84). Ces remarques sur le caractère accompli de cet aède, probable projection du poète lui-même, sont en pleine convergence avec l'« achievement » dont parle (p. 53) J. Griffin, The Epic Cycle and the Uniqueness of Homer, in JHS, 97 (1977), p. 39-53.

170 Cf. Rudhardt, 1971 (supra, n. 148), p. 84 sq. Si l'aède se trouve au centre des évolutions du xopós, tout comme l'Ourse voit les corps célestes tourner autour d'elle, on pourrait poursuivre le parallèle en avançant que l'incapacité d'Arctouros à bénéficier d'une régénération dans les eaux primordiales est la même que celle du poète à immortaliser les héros autrement que par la Mémoire (sur poésie et Mémoire, $c f$. D. Bouvier, L'aède et l'aventure de mémoire. Remarques sur le problème d'une dimension religieuse de la mémoire dans l'́liade et l'Odyssée, in Ph. Borgeaud (éd.), La Mémoire des Religions, Genève, 1988, p. 63-78, spéc. p. 68). Ainsi retrouverions-nous dans cette ouverture cosmique à la fois l'amorce d'une représentation cyclique (sensible dans le verbe

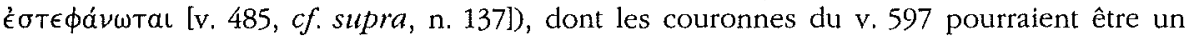
pendant) qui court dans tout le poème, et une figuration des pouvoirs du poète dans toute leur splendeur et leur étendue, mais aussi dans leurs limites.

${ }^{171}$ On peut rapprocher ce procédé de l'averse de sang que Zeus avait fait pleuvoir pour rendre hommage à Sarpédon avant sa mort : $l l$. XVI, 459-60. La présence concomitante au ciel des Pléiades, des Hyades et d'Orion indique nécessairement les environs du 10 novembre ( $C f$. LE BøuffLe, Les noms latins [supra, n. 169], p. 274-275), c'est-à-dire le début de l'hiver - sur la valeur symbolique des intempéries dans l'Iliade, $c f$. Bouvier, Tempête (supra, n. 27), p. 250-252. Notons, parmi ces trois constellations (mises au beau 


\section{Conclusion}

Donc non seulement la scène du xopós (tout comme celles qui la précèdent) est intimement tissée $\mathrm{e}^{172}$ avec d'autres termes du Bouclier autant qu'avec le reste du poème, mais encore elle en remodèle la matière même selon une autre alchimie. Le chef-d'œuvre conçu par le dieu forgeron paraît bien être un tout qui reprend sur un plan transcendé l'équivalent plastique des deux modes narratifs de l'Iliade, déjà figuré par les deux manteaux

milieu, v. 486, de cet ensemble de sept vers qui sert d'ouverture cosmique), l'importance singulière accordée à Orion dont il est encore question au v. 488, dans des conditions assez curieuses; car on relèvera l'étrangeté du verbe $\delta$ ok $\in \dot{\epsilon} \epsilon$, pour deux constellations que sépare en longitude un écart de près de cent degrés ( $c f$. A. Le Bceuffle, $\dot{A}$ propos $d u$ "Retour des Argonautes", in $B A G B$ [1966], p. 119-120). La grande distance qui sépare l'Ourse d'Orion oblige à se tourner vers une valeur plutôt allégorique pour l'expression

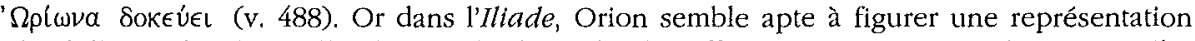
d'Achille. D'abord en effet il possède de probables affinités avec un autre chasseur, Méléagre, donné explicitement comme un paradigme mythique d'Achille : $c f$. M.M. WILLCock, Mythological Paradeigma in the Iliad, in CQ, 14 (1964), p. 141-165; Aubriot, Il. IX (supra, n. 13), p. 357-359; sur Orion, $c f$. la thèse (en préparation) de Jean-Michel RENAud - qui fera suite à son étude Le mythe de Méléagre. Essais d'interprétation, Liège, 1993. Mais surtout Achille tournant autour de Troie, resplendissant dans son armure comme un astre sinistre d'arrière-saison éclatant parmi les étoiles, est d'abord comparé au Chien d'Orion (XXII, 29), pour être assimilé un peu plus loin (au moment fatidique de la mort d'Hector), à l'astre du soir (Eomepos, v. 317-318; cf. LE BøuffLe, Les noms latins [supra, n. 169l, p. 237) - deux passages qui sont intimement liés par leur second hémistiche

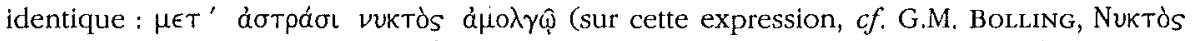
$\dot{\alpha} \mu \mathrm{o} \gamma \hat{\omega}$, in $A J P b, 79$ [1958], p. 165-172; elle signifierait « à l'heure de la traite du soir », et serait donc un nouvel exemple de la juxtaposition tragique dans l'Iliade entre vie tranquille et mort imminente). Sur la valeur symbolique d'Orion dans le combat, $c f$. Bouvier, Tempête, p. 249. Le catastérisme d'Orion pourrait donc constituer une médiation mythique particulièrement appropriée pour figurer un Achille («épié » par l'aède) poétiquement sidéral, mais non cultuellement éternel. En tout cas, il paraît hautement indiqué d'introduire un rapport direct entre les corps célestes et le récit épique (aussi bien a-t-il été souligné que ce qu'on nomme l'aristeia d'Achille était accompagnée d'images non plus animales, comme pour les autres combats, mais cosmiques; ScHNAppGourbeillon, Lions, béros et masques [supra, n. 29], p. 84-85).

172 Là est bien le travail supposé par le mot grec ǔ $\mu \nu$ os comme par le français «texte ». Aussi les figures dessinées par les choeurs sont-elles également une sorte de «tissage »-cf. Calame, Cboeurs (supra, n. 108), I, p. 77-78. En plus des références mentionnées supra, n. 102, et dans Aubriot, 1997a (supra, n. 9), n. 10, on pourra consulter BADER, La langue des dieux (supra, n. 38), p. 22, et Héraclès, Ogmios, et les Sirènes, in Héraclès II, Les femmes et le féminin, Actes du colloque de Grenoble (oct. 1992), Institut historique belge de Rome, 1996, p. 145-185, spéc. p. 167. Aussi n'y a-t-il aucune antinomie entre les tenants de l'opinion que l'Iliade est une ouvre d'art formant un tout (comme Whitman, Sheppard, Basset : $c f$. supra, n. 13), et ceux qui mettent l'accent sur l'importance qu'y revêtent parataxe et digressions (cf. Austin, 1966 [supra, n. 11], p. 295-296). On trouvera une bibliographie des métaphores artisanales définissant l'activité du poète dans $\mathrm{Cl}$. Calame, Le proème des Travaux d'Hésiode, prélude à une poésie d'action, in Le métier du mythe, (supra, n. 91), p. 169-189, spéc. p. 177, n. 22. 
d'Hélène et d'Andromaque ${ }^{173}$, en ce qu'ils représentaient l'un la guerre meurtrière et l'autre les fleurs des champs ${ }^{174}$. À considérer la structure des différentes représentations plastiques mentionnées dans le poème - qu'elles décorent une œuvre textile ou métallique -, on se persuade qu'elles permettent d'appréhender de plus près le système poétique de l'Iliade et sa signification, en présentant parallèlement des équivalents figurés des deux registres poétiques de l'œuvre, et qu'elles pourraient ainsi revêtir une valeur de miroir du récit épique, propre à faire retrouver dans la texture ${ }^{175}$ même de l'épopée la réversibilité qui semble en marquer la composition. Mais le Bouclier est bien plus encore que cela : à cette composition en chiasme de la centaine de vers qui suit le cosmos (v. 490-589), le couronnement du Xopós invite à superposer un double mouvement orienté à chaque fois vers une interprétation poétique et musicale : celle de l'enfant exécutant un Linos, qui vient clore une sorte de parabole de l'Iliade; celle de l'aède divin, qui donne la clef d'une volée de vers plutôt symbolique de l'art du poète épousant le point de vue du dieu et rivalisant avec son art. C'est en effet bien là que semble résider l'originalité de l'Iliade : ces deux aspects (qu'on pourrait, non sans anachronisme, qualifier d'artistique et de métaphysique) y sont inextricablement liés. Tout comme d'une manière générale avec le personnage d'Achille ${ }^{176}$ le poète explore les limites entre humanité et divinité, ici il brouille l'identification de l'auteur, en favorisant la confusion entre bouclier et Bouclier : si c'est le dieu qui est censé représenter l'aède, cette représentation figure sur une œuvre dont la seule existence, en fin de compte, est poétique. Le tour de force - dont la réussite effective revient au poète et non au dieu - est de présenter poétiquement l'œuvre plastique d'un dieu, et ce, de manière à laisser percevoir une gradation entre l'usage traditionnel de l'épopée et la sublimation qui en est ici offerte. C'est le dieu qui est présenté travaillant avec plus de distance mais de manière plus directe que les tapissières et même que le narrateur : plus de distance en ce qu'il ne rapporte les scènes des villes à aucune guerre particulière, et de manière plus directe,

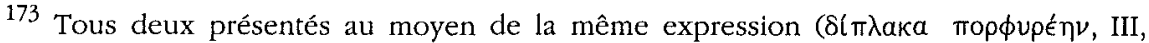

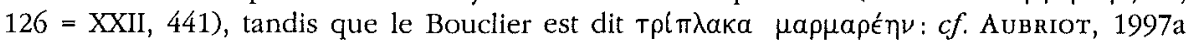
(supra, n. 9), p. 26.

174 Sur cette question des valeurs symboliques de ces deux étoffes et de leur complémentarité (tant entre elles que par rapport au Bouclier), cf. Auвriot, 1997a (supra, n. 9). Par ailleurs, Beскеr s'est déjà (d'un autre point de vue) montré sensible aux ressemblances entre l'art du poète dans la description du Bouclier et dans le reste de l'épopée (cf. supra n. 3).

175 Une semblable attention portée ici par «Homère » aux techniques du récit confirmerait la nécessité de mettre, de ce point de vue, l'lliade sur le même pied que l'Odyssée, qui passe depuis longtemps pour un modèle d'utilisation consciente de ces techniques. Cela rend naturellement inévitable qu'on se pose à nouveaux frais la question de l'auteur.

176 Cf. Aubriot, Humanité el divinité dans l'dliade (supra, n. 5). 
car les scènes de campagne reprennent sans médiation le contexte des comparaisons. Par là est marquée, semble-t-il, la différence de l'accommodation de son regard sur le monde. De plus il doublerait chacun de ces deux volets (guerrier et champêtre) de la vie, d'un prolongement sur la mort présentée tantôt comme un carnage sanglant qui assène une fin brutale, tantôt comme une disparition qui, pour revêtir des couleurs moins effrayantes, n'en est pas moins un anéantissement. Enfin et surtout le Bouclier, outre qu'il réunit en les dépassant les perspectives des deux hérö̈nes, leur ajoute celle du dieu, à qui sa nature permet de considérer d'un point de vue supérieur ${ }^{177}$ les vicissitudes de la vie humaine et partant d'abolir dans la dernière scène jusqu'aux notions d'espace et de temps. Sans doute est-ce pourquoi sur le chef-d'œuvre divin le double est devenu triple, et la pourpre - royale sans doute, mais aussi reflétant l'agitation ${ }^{178}$ - a cédé place à la splendeur adamantine et immortelle. C'est que les deux registres du poème (celui du récit de la guerre et celui du contre-récit jouant sur les comparaisons), repris en surimpression et selon des éclairages inversés, résonnent ici en harmonie avec une troisième voix, celle du plaisir offert par les exécutions artistiques habiles qui permettent aux mortels une sorte de participation provisoire au plaisir des dieux ${ }^{179}$. Le vertige que fait naître leur évocation parvient à résoudre l'antagonisme fondamental de l'ouvre poétique en superposant la vie et la mort dans cette image réfléchie impossible à représenter qu'est le Bouclier : au moins autant qu'un microcosme ou « Imago mundi » $(\mu\{\mu \eta \mu \alpha$ kó $\sigma \mu o v)$, il serait «Imago Iliadis », une image de l'Iliade, renvoyée comme dans un miroir ${ }^{180}$ convexe; plus petite dans ses dimensions, mais focalisée, brillante, et reflétée à l'envers. Mais cet effet, si réussi soit-il, ne doit sans doute pas voir son appréciation bornée à l'admiration esthétique : il ne semble pas dissociable de la vision du dieu, détachée des contingences humaines, et de l'offrande, unique en son genre, d'une œuvre spécialement conçue pour lui, que fait Héphaïstos au mortel singulier qu'est le fils de

177 Quoique - trait extrêmement significatif - ce dieu soit de ceux qui ont souffert : les v. 395 \& 397 de ce chant XVIII montrent que, de la douleur (physique ou intime), Héphaïstos a connu ou frôlé toutes les nuances.

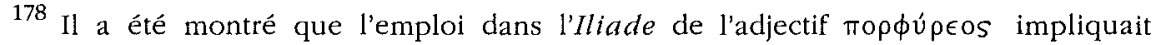
toujours quelque agitation (cf. Amandine Toupet, Autour des couleurs dans litiade, Mémoire de Maîtrise soutenu à l'Université d'Amiens, 1996, dactyl.).

179 Plaisir sans mélange pour les dieux, plaisir consolateur pour les hommes : $c f$. supra, n, 161.

180 Il n'est pas inhabituel que certains passages de l'lliade en reflètent d'autres : outre F. Létoublon ( $c f$. supra, n. 12), on citera entre autres Irene J.F. DE JoNG, Iliad $1,366-392$; A Mirror Story, in Arelbusa, 18 [1985], p. 5-22; Aubriot, Il. IX (supra, n. 13), p. 260-265 (reflets du chant I au chant IX). Mais pour le Bouclier, le procédé est porté à un degré de généralisation et de perfection inégalé (Aubriot, 1997a [supra, n. 91). Aussi bien un certain nombre de tentatives ultérieures pour représenter ce bouclier l'ont-elles montré comme une surface convexe réfléchissante : cf. HaRdie (supra, n. 1), p. 19-20. 
Thétis et de Pélée. Aussi pourrions-nous reprendre à notre compte, en son

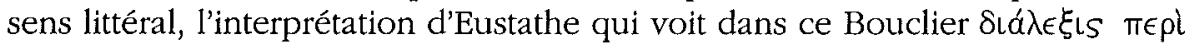
$\theta \epsilon i \omega \nu$ кal ả $\theta \rho \omega \pi i v \omega \nu(1155.2)^{181}$.

Danièle AubrioT

26, place de la République

F - 80290 PoIx

181 Les réflexions proposées ici reprennent, après remaniements substantiels, une partie d'un exposé présenté d'abord à Genève, sur l'invitation de $M$. André Hurst et de Mme Alessandra Lukinovitch en décembre 1995, puis devant l'Association des Études grecques à Paris en janvier 1996. Que tous ceux qui ont bien voulu mapporter critiques et suggestions lors des discussions qui ont suivi, puis dans les phases ultérieures de ce travail, soient chaleureusement remerciés. Je me sens une dette particulière envers tous mes collègues belges qui n'ont cessé de m'aider de toutes les manières, et qui finalement ont bien voulu accepter de publier cet article dans la revue Kernos. Nul d'entre mes amis liégeois ne trouvera à redire, que mes pensées de reconnaissance se concentrent sur le souvenir du regretté Jules Labarbe : jusqu'à la limite de ses forces il m'a fait part de ses remarques, de ses encouragements. C'est avec une profonde gratitude que je dédie ce travail à sa mémoire. 